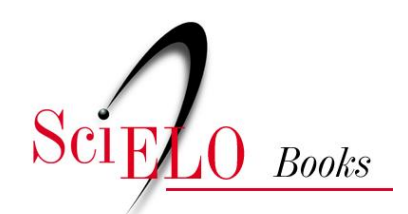

\title{
"¡Y qué saben ellos!" (Re)flexionando relaciones epistémicas entre cultura, escritura y naturaleza desde el ámbito andino
}

\author{
Fernando Garcés V.
}

\section{SciELO Books / SciELO Livros / SciELO Libros}

GARCÉS V., F. “¡Y qué saben ellos!” (Re)flexionando relaciones epistémicas entre cultura, escritura y naturaleza desde el ámbito andino. In: GARCÉS, F., and BRAVO, R., eds. Interculturalidad.

Problemáticas y perspectivas diversas [online]. Quito: Editorial Abya-Yala, 2019, pp. 75-121. ISBN: 978-9978-10-497-2. https://doi.org/10.7476/9789978104972.0004.

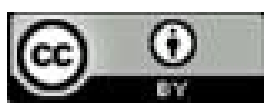

All the contents of this work, except where otherwise noted, is licensed under a Creative Commons Attribution 4.0 $\underline{\text { International license. }}$

Todo o conteúdo deste trabalho, exceto quando houver ressalva, é publicado sob a licença Creative Commons Atribição 4.0.

Todo el contenido de esta obra, excepto donde se indique lo contrario, está bajo licencia de la licencia $\underline{\text { Creative }}$ Commons Reconocimento 4.0. 


\section{"iY qué saben ellos!" (Re)flexionando relaciones epistémicas entre cultura, escritura y naturaleza desde el ámbito andino}

Fernando Garcés V. Universidad Politécnica Salesiana

\section{Introducción}

Hace treinta años, cuando se creó la Dirección Nacional de Educación Intercultural Bilingüe en Ecuador, el horizonte discursivo de la interculturalidad estaba centrado en el ámbito educativo. Hoy pensamos la interculturalidad en multiplicidad de contextos y desde distintas perspectivas e intereses.

El presente capítulo intenta ofrecer pistas de reflexión sobre interculturalidad epistémica desde dos ámbitos "problemáticos": 1) la relación escritura alfabética vs. otras escrituras, y 2) las concepciones y ontologías diversas de lo natural y cultural. Si la interculturalidad no sólo tiene que ver con los interrelacionamientos de varios actores sino con sus formas de entender y portar el mundo es necesario reflexionar sobre las posibilidades reales de dialogar — no imponer, fagocitar o integrar-interepistémicamente.

En el sentido antedicho, el texto que sigue (muy poco interepistémico y bien "occidentalote") no se basa en seguridad alguna. Sólo pretende hacer aquello a lo que siempre me invitaba Don Isidoro de Tirajhoyo: "caminaremos Don Fernando; caminando nos conversamos y conversando nos vamos aclarando". 


\section{El debate sobre interculturalidad}

Es bastante conocido que el debate sobre la interculturalidad se instaló a partir de la década del 70 y con mayor intensidad a partir de los 80, principalmente en el ámbito educativo y a demanda de los pueblos indígenas (Walsh, 2001, 2002). Luego, el término y la reflexión se extendieron a campos diversos como el derecho, la política, la salud, la filosofía, la comunicación, etc. (Fuller, 2005; Orellana, 2004; Rodrigo, 1999; Fornet-Betancourt, 2001).

Visto en una perspectiva más amplia, el debate sobre lo intercultural tiene que ver con el valor que se le otorga a la diversidad tanto desde los procesos de flexibilización del capitalismo como desde la pluralidad de las luchas sociales (Garcés, 2010, 2011). Así, el imaginario de unidad nacional, de lucha proletaria como única salida revolucionaria y el modelo de producción en serie dan muestra de fractura desde los años 70 del siglo pasado.

Las conceptualizaciones de lo intercultural se han movido desde el ámbito de lo descriptivo hasta las valoraciones que tratan de dar cuenta de lo verdaderamente intercultural. En el primer polo se encuentran aquellas que dan cuenta de la diversidad y sus formas de relacionamiento, mientras en el segundo se intenta formular el carácter preciso de lo intercultural, generalmente mediante el añadido adjetivo de "crítica” (Viaña et al., 2009). Veamos algunas de estas concepciones.

Las concepciones descriptivas, funcionales, "neutras", han sido etiquetadas por Catherine Walsh como multiculturalidad y pluriculturalidad. En el primer caso se trata de un interrelacionamiento cultural basado en la tolerancia y en la separación. La multiculturalidad o multiculturalismo se entiende como la simple constatación de la existencia de culturas diversas en un determinado espacio sin hacer referencia a sus mutuas relaciones (Albó, 1999; Walsh, 2002). Esta práctica y concepción opera en el orden descriptivo y bajo los principios liberales de individualidad, igualdad y tolerancia hacia el otro (Kymlicka, 1995, 2001; Taylor, 1992; Walzer, 1997). Se trata, no obstante de un principio 
que oculta la existencia de desigualdades sociales, dejando intactas las estructuras e instituciones de privilegio (Walsh, 2001). ${ }^{1}$

En el caso de la pluriculturalidad se reconoce la diversidad cultural existente en un territorio, incluso se la celebra, pero se lo hace desde el centro de la cultura dominante y "nacional” (Garcés \& Guzmán, 2003, p. 20). En este contexto se ve la diversidad cultural como una riqueza que se incorpora al modelo y a la estructura política del Estado-nación, sin cuestionar sus mecanismos de dominación. Es el modelo que fue el adoptado en muchos países de Latinoamérica a propósito de la implementación de las políticas de la diferencia desplegadas hacia fines de los 80 y la década del 90 (Garcés, 2009).

En cualquiera de estas versiones, lo que tenemos es la ausencia de una teoría del poder (Paz, 2005a, 2005b, 2006); es decir, se considera las interrelaciones culturales como prácticas desprovistas de conflictividad, dominación, agencia o resistencia. En definitiva, se idealizan las interacciones sociales y culturales dadas por grupos diversos.

Lo propiamente intercultural estaría definido, por Walsh, en términos de relaciones complejas, negociaciones e intercambios de múltiple vía. El punto de partida es el reconocimiento de que las relaciones entre los grupos culturales están marcadas por el conflicto fruto de las desigualdades sociales, económicas y políticas. El horizonte es la construcción de algo inexistente: relaciones equitativas a nivel de personas, colectivos, conocimientos y prácticas. En tal sentido, no se trata de un simple reconocimiento del otro o de actitudes tolerantes hacia el otro; tampoco se trata de la definición o reconocimiento de identidades étnicas fijas, esencializadas e inamovibles. Se trata de prácticas en construcción y enriquecimiento en el conflicto y en el forcejeo por lograr espacios de poder (Walsh, 2002; Garcés \& Guzmán, 2003, p. 20).

Esta concepción de interculturalidad tiene relación con la reflexión sobre las identidades que se ha debatido en las últimas décadas. En la concepción moderna la identidad ha sido pensada como una enti-

1 Para una crítica al multiculturalismo como enfoque teórico-político que busca insertar la diversidad en el sistema de dominación global, véase Díaz-Polanco (2006). 
dad estable, permanente, fija y esencial. Desde la crítica posmoderna se plantea que esta forma de concepción propugna una racionalidad totalizante, binarista, esencializante; ciega y anuladora de otras racionalidades (Lyotard, 1990). ${ }^{2}$ Así, el principio de esencialidad fija determinadas características a identidades de sujeto (Vattimo, 2000). En tal sentido, la posmodernidad se caracteriza por la exaltación de los juegos flexibles, la descentración del sujeto y la movilidad de las relaciones significadosignificante (Lander, 1995; Lyotard, 1990). Como dice Vattimo, "el ser no coincide necesariamente con lo que es estable, fijo y permanente, sino que tiene que ver más bien con el evento, el consenso, el diálogo y la interpretación" (2000, p. 22).

Esta mirada es la que ha permitido comprender las identidades políticas subalternas en términos relacionales y relativos (Coronil, 2000; Mallon, 2001), lo cual ha llevado, por un lado, a una efervescencia de la expresión plural de las identidades de sujetos y, por otro lado, a redefiniciones continuas de los lugares de dominación, resistencia y participación de los colectivos sociales identitarios. Wade (1997), por ejemplo, destaca que las identidades étnicas y raciales deben verse en contexto nacional y global como construcciones cambiantes, flexibles y relacionales con el género, la religión, la sexualidad, poniendo sobre la mesa el tema de las resistencias y de la relacionalidad y continuidad cultural.

La teoría crítica moderna no pudo escapar de la designación de un único sujeto transformador de la historia y agente subsumidor y condensador de otras posibles identidades. En los filones comprensivos contemporáneos se enfatizará, por el contrario, en la pluralidad de actores, propuestas y teleologías estratégicas que caracterizan las luchas por el poder y la definición del campo político, expresadas en posiciones referentes al género, a la sexualidad, a la "raza", a la cultura, a la generación, etc., incluyendo la clase en este etcétera ya que no es posible pensar la diferencia haciendo abstracción de la jerarquía (Wieviorka, 2001; Wade,

2 La presentación de modernidad/posmodernidad no sugiere, de modo alguno, que se trate de una correlación en términos de anterioridad-sucesión, sino como posiciones divergentes y contrapuestas en cuanto a su comprensión de lo identitario. 
1997). Obviamente, esto significa no sólo una pluralidad de actores sino también de proyectos emancipatorios o liberadores que requieren dialogar entre sí. A este respecto, Santos (2000) propone que no habiendo un principio único posible de transformación social, no habiendo agentes históricos de transformación únicos, no habiendo una forma única de dominación, lo que se necesita en la contemporaneidad de las luchas sociales no es tanto una teoría común sino una teoría de la traducción que haga mutuamente inteligibles las luchas.

Pero por otro lado, la crítica a la razón moderna y el énfasis en la flexibilidad de las dinámicas identitarias tienen también varios riesgos tales como: a) una politización de la cultura a la par de una despolitización de la política y la economía; b) un optimismo cuasi ciego de las potencialidades emancipatorias de la diferencia; y c) un énfasis fuerte en las luchas fragmentadas que se separan del concepto de totalidad social (Garcés, 2011).

En términos epistémicos el debate sobre interculturalidad se puede discutir sobre la base de la crítica a la hybris del punto cero planteada por Santiago Castro-Gómez. Este habría sido el mecanismo mediante el cual el conocimiento de la modernidad colonial se constituyó en un conocimiento superior, atribuyéndose un punto de mirada "neutro", "una forma de conocimiento humano que eleva pretensiones de objetividad y cientificidad partiendo del presupuesto que el observador no forma parte de lo observado" (Castro-Gómez, 2005a, p. 63). Al igual que el Deus absconditus de los griegos, esta forma de conocimiento permite ver sin ser visto, permite "observar el mundo sin tener que dar cuenta a nadie, ni siquiera a sí mismo, de la legitimidad de tal observación; equivale, por tanto, a instituir una visión del mundo reconocida como válida, universal, legítima y avalada por el Estado" (2005a, p. 63). Para ello, durante el siglo XVIII, los representantes de la Ilustración buscan crear un metalenguaje universal: el de la ciencia (Pratt, 2010).

El lenguaje de la ciencia permitiría generar un conocimiento exacto sobre el mundo natural y social, evitando de este modo la indeterminación que caracteriza a todos los demás lenguajes. El ideal del científico ilustrado es tomar distancia epistemológica frente al lenguaje cotidiano — considerado como fuente de error y confusión— para ubicarse $[\ldots]$ 
[en] el punto cero. A diferencia de los demás lenguajes humanos, el lenguaje universal de la ciencia no tiene un lugar específico en el mapa, sino que es una plataforma neutra de observación a partir de la cual el mundo puede ser nombrado en su esencialidad. Producido ya no desde la cotidianidad [...] sino desde un punto cero de observación, el lenguaje científico es visto por la Ilustración como el más perfecto de todos los lenguajes humanos, en tanto que refleja de forma más pura la estructura universal de la razón. (Castro-Gómez, 2005b, p. 14)

En este contexto el autor se planea dos tipos de "tareas", una hacia dentro de la academia y la ciencia y otra en relación con otros conocimientos. La primera apostaría por la transdisciplinariedad como una forma de superar la marca moderna que veía la realidad de forma fragmentada y compartimentada. En este sentido:

La idea de que cada uno de nosotros es un todo físico-químico-biológico-psicológico-social-cultural, integrado en la compleja trama del universo, ha dejado de ser vista con sospecha por muchos hombres de ciencia, por académicos e intelectuales de todo el mundo. Desde la física, la biología, la neurociencia, la antropología, la sociología y la psicología contemporáneas, se empiezan a revisar, implícita o explícitamente, los presupuestos epistémicos que marcaron la hybris del punto cero. (Castro-Gómez, 2007, p. 86)

Se trata, entonces, de echar a andar un programa, por lo menos, interdisciplinario o, mejor aún, transdisciplinario; es decir, una apuesta por la superación de las divisiones entre las distintas ciencias (Morin, 1999). Como se sabe, la gran división, casi inobjetable, al interior de las ciencias se da entre ciencias naturales y ciencias sociales (Eco, 1988; Zecchetto, 2002). ${ }^{3}$

3 Existe un amplio debate y propuestas de trabajo inter y transdisciplinario en las ciencias, en general, y en las ciencias sociales de manera específica. Por el objetivo de esta comunicación no podemos abordar esta tarea propuesta por CastroGómez. Puede consultarse, al respecto, Agazzi (2002); Fernández (2004); García (2011); Leff (2015); Maldonado (2009); Orejuela (2009); Wallerstein (1996, 1998). 
La segunda "tarea" propuesta por Castro-Gómez es trabajar sobre la construcción no sólo transdisciplinaria sino transcultural del conocimiento (Castro-Gómez, 2007); en esta perspectiva se trata de replantearse la manera como Occidente se relaciona con los otros conocimientos, ya no acercándose $a$ ellos para conocerlos sino justamente para dialogar con ellos (Garcés, 2009). ${ }^{4}$

Sobre la base de este planteamiento pienso que en el diálogo epistémico entre "occidente" y los "otros" hay varios problemas, de los que quisiera tomar dos como elementos de reflexión en esta comunicación: 1) las posibilidades epistémicas desde la apropiación o no de la escritura alfabética, ya que occidente ha construido la escritura como absoluto gnoselógico mientras en otros pueblos existen otros sistemas de inscripción que tienen centralidad expresiva; y, 2) la separación cultura/ naturaleza propia también de Occidente mientras muchos pueblos indígenas no establecen escisiones tajantes en dichos ámbitos.

\section{Escritura e interculturalidad epistémica}

Sobre lo primero, ya decíamos que el tema de la interculturalidad se desplazó a varios campos de prácticas y conocimientos. Uno de ellos fue precisamente el debate sobre las posibilidades de diálogo entre distintas formas de conocer, entre distintas formas de aprehender y expresar el mundo, es decir, sobre lo que se podría llamar una interculturalidad epistémica.

¿Cómo se conoce el mundo y cómo se expresa el mundo conocido? Sin entrar en los debates sobre inmanentismo y empiricismo (Garcés, 1997) el tema es que hay determinados tipos de conocimientos que tienen más valor y ello se debe a que son conocimientos que se los evalúa en referencia a su correspondencia con la realidad; es decir, por su capacidad

4 Si bien el término "Occidente" es polisémico y hace referencia a una multiplicidad de expresiones culturales, históricas y epistémicas, por un lado, y ha estado marcado por las diferentes concepciones y aportes culturales, por otro, lo tomamos aquí como una totalidad política y epistémica con base en la autodenominación surgida en la Edad Media europea. 
de ser expresión de lo "real". Este es el valor que se le da al conocimiento científico: aun tomando distancia del positivismo que concebía la ciencia como una fotografía de la realidad, ella se evalúa en esos términos, es decir, por su capacidad explicativa de lo que ocurre en el mundo. Tal adecuación de la ciencia a los hechos de la realidad tiene un canal de expresión específico: la escritura (alfabética). No sería posible concebir el desarrollo de la ciencia sin la existencia acumulativa de la escritura (alfabética). De manera que cabe la pregunta, ¿cómo pensar la interculturalidad epistémica desde la centralidad de un tipo de escritura que se ha entronizado como la única capaz de producir conocimiento legítimo y válido?

Paradójicamente, a pesar de la centralidad que ha adquirido la escritura (alfabética) en occidente, o tal vez por ello, no ha habido un suficiente desarrollo teórico sobre ella (Harris, 1995). La historia de su estudio y reflexión ha estado tan vinculado a la lingüística y a pensarla como graficación del habla que los esfuerzos por desplegar una teoría de la escritura han sido mínimos y, cuando se han dado, salvo algunas excepciones, el punto de partida ha sido la escritura alfabética. Si seguimos la idea de Derrida (1967a, 1967b) de la primacía del logos verbal y le añadimos el ingrediente de ver la escritura como copia de tal oralidad, tenemos esa práctica y conocimiento fonocéntrico que ha adquirido la escritura. La base sigue siendo una concepción lingüística, es decir, tomando la representación sonora en lugar de tomar la categoría de signo como punto de partida. De tal forma que un buen inicio sería trabajar sobre una concepción semiótica de la escritura antes que lingüística (Harris, 1995; Garcés, 2017). Y ello no sólo como una suerte de concesión a sociedades de supuesta tradición ágrafa, como en el caso del qhichwa/ kichwa, sino como parte del despliegue de los recursos visuales expandidos con fuerza el día de hoy (Garcés, 2017).

Etnografías y testimonios del pasado y del presente dan cuenta de la manera como se han usado escrituras logográficas en distintos lugares del orbe, ${ }^{5}$ muchas de ellas articuladas a formas fonográficas, no como

5 La escritura logográfica o semasiográfica está orientada a expresar el contenido, el significado de las palabras y puede incluir tanto lo que tradicionalmente se denominaba pictografía como ideografía (Garcés, 2017, p. 29). 
parte de despliegues evolucionistas sino como recursos de indiferente utilidad, tal como se atestigua en la escritura azteca y china, por ejemplo (Garcés, 2016).

En el ámbito andino existe un amplio debate en el mundo académico sobre si hubo o no una escritura precolonial (Szemiński, 2010; Jaye \& Mitchel, 1999). El debate es importe debido a que se plantea que en un espacio sociogeográfico que albergó grandes civilizaciones y Estados (Tiahuanacota e Inca), debió existir mecanismos de registros contables, al menos, cuando no históricos o normativos.

Como se sabe, el surgimiento de la escritura (alfabética) se suele asociar con el desarrollo de los estados. Hace 5500 años, en las llanuras de los ríos Eufrates y Tigris (actual Irak) nacieron las primeras ciudades y con ellas una nueva forma de organización política, ya no estructurada según redes de parentesco sino bajo una nueva burocracia administrativa permanente que exigía lealtades por encima del linaje o del clan. En este contexto, los jefes locales cedieron gran parte de su autoridad en favor de una clase dirigente que tenía el poder de acumular un excedente agrícola y movilizar mano de obra para llevar a cabo proyectos de irrigación a gran escala y arquitectura monumental. En ciudades como Ur y Uruk, con más de 40000 personas, aparece una casta profesional de sacerdotes que se responsabiliza de la compleja religión de santuarios, al tiempo que también surgen especialistas artesanos que manufacturan cuchillos de obsidiana y estatuillas de oro y plata y se establecen redes comerciales (Lewellen, 2003).

De esta manera habría surgido el Estado. En su versión inicial, encontramos esta nueva forma de organización política en Mesopotamia como fruto de un proceso de adaptaciones a un hábitat particular y a un conjunto específico de problemas sociales. Este proceso también se dio en otros lugares y tiempos, conformando los llamados Estados "prístinos", generalmente ubicados en valles o en zonas mesopotámicas (entre ríos): Sumeria (entre el Tigris y el Eufrates), Egipto (Valle del Nilo), India (Valle del Indo), China (Valle del Río Amarillo), Mesoamérica (Olmeca, Teotihuacán) y los Andes (Chavín, Tiahuanaco). Estos estados prístinos surgieron de manera independiente a pesar de su distancia geográfica y temporal (Lewellen, 2003). 
Por otro lado, se considera que los desarrollos escriturarios más importantes se habrían efectuado hacia el 3000 a.C., como postula DeFrancis (1989). Winand (2013) vincula estos desarrollos con Mesopotamia, Egipto, China, Mesoamérica, India y la Isla de Pascua:

Dans l'histoire mondiale, l'ecriture apparaît pour la pemière fois dans quatre foyers: en Mésopotamie et en Égypte, aux environs de 3300, en Chine à la fin du IIe millénaire et en Amérique centrale au milieu du Ier millénaire av. J.C. (Winand, 2013, p. 4)

Á cela, il faut peut-être ajouter les écritures de l'Indus et de l'île de Pâques (rongorongo). (Winand, 2013, p. 4)

Pareciera, entonces, que habría una vinculación casi directa entre surgimiento de estados y desarrollo escriturario. Es decir, los procesos de urbanización que dieron lugar a aquellas aproximadamente 13 ciudades-Estado de Sumeria (Lewellen, 2003, p. 69) habrían creado la necesidad de registro para el control estatal.

La distinción con los llamados grupos tribales es clara. Las sociedades llamadas tribales no tienen sistema de escritura, no forman estados y no tienen una religión institucionalizada universalista y proselitista basada en el libro. En cambio, las sociedades estatales tienen un sistema de registro (escritura) que les permite controlar los recursos (administración), los grupos de poder (política) y la ideología (religión). Por eso manejan una religión institucionalizada basada en el dogma y en el libro. El esquema sería entonces que el Estado necesita controlar: a) los recursos (por medio de la administración y la contabilidad); b) los grupos de poder (por medio de las leyes); y, c) la ideología (por medio de la religión). Y todos estos tres ámbitos se vehiculan por la escritura (Garcés, 2005). ${ }^{6}$

El problema es que los Andes no calzan en este modelo. ¿Cómo pudo un Estado como el incaico administrar un amplio territorio sin contar con una escritura alfabética como la desarrollada en los estados prístinos?

6 Sobre las vinculaciones de la escritura con los aparatos religiosos, políticos y administrativos de los sistemas dominantes, véase Goody (1968, pp. 11-16). También Landaburu (1998, p. 82). 
En el ámbito andino, los esfuerzos de encontrar una escritura de similitud con la alfabética han sido desarrollados entre otros, por Jara (1975) y Burns (1981). Sus propuestas de ver morfemas o grupos silábicos en los tocapus incaicos no han tenido acogida entre los investigadores, recibiendo incluso críticas de parte de los lingüistas del área andina.

En las últimas décadas se ha desplegado un esfuerzo importante por investigar formas de inscripción de información y de memoria en distintos soportes y mecanismos (Bouysse-Cassagne, 2000). Así, se cuenta con investigaciones sobre piedras y granos de maíz (Curatola \& de la Puente, 2013), qirus (Martínez et al., 2014), textiles y talegas (Arnold, 2012; Cereceda, 2010), varas de mando (Salomon, 2004), cerámica (Bray, 2004), khipus (Urton, 1998), tocapus (De Rojas, 2008), producciones visuales rupestres (Cruz, 2016), etc. Por otro lado, se han realizado análisis de las informaciones proporcionadas por las crónicas, especialmente las de Sarmiento de Gamboa (1572), Acosta (1590), Molina (c. 1575), Murúa (c. 1615), Pachacuti Yamqui (c. 1613), Guamán Poma (1615). En ellas se ha hurgado tanto en la forma en que se consignaba la información (Acosta, Sarmiento de Gamboa y Molina) como en los propios performances escriturarios (Guamán Poma, Murúa y Pachacuti).

Hoy en día estamos en condiciones de afirmar que en el ámbito andino se contaba con distintas escrituras selectivas (Déléage, 2013) que funcionaban de manera discrecional, sobre distintos templetes, y que servían para expresar distintos ámbitos de la realidad social (Garcés y Sánchez, 2016).

Así, Arnold (2012) afirma que los textiles podían ser leídos como repositorio documental para el ámbito tributario; los qiru parecen narrar historias oficiales incaicas (Ziólkowski et al., 2008); las varas de Tupicocha funcionan como escritura sin palabras para organizar las relaciones sociales de la comunidad y el Estado (Salomon, 2004); los khipu, cuando menos, funcionan como recursos contables y mnemotécnicos (Chirinos, 2010); y, los textos logográficos/tridimensionales habrían desarrollado temas explícitamente religiosos (Ibarra, 1953).

Estaríamos, por lo menos a nivel de hipótesis, ante formas de inscripción diferenciada que, entre otros aspectos, nos obligarían a repensar los vínculos entre desarrollo escriturario y formaciones estatales. Así lo atestiguan varias fuentes coloniales tempranas. 
El instrumento más conocido y estudiado como medio de comunicación no presencial es el quipu (Urton, 1998; Salomon, 2004). Hoy en día se sabe que el quipu servía para registrar datos cuantitativos estatales en relación a producción, población y tributos; pero también como base material para la realización de ceremonias, la resolución de asuntos de paz y de guerra, para la recitación de historias. Con el quipu podían escribirse leyes, cuentas de negocios, de tierras, de ganado, etc. (Chirinos, 2010; López, 1998; Salomon, 2004).

José de Acosta, en 1590 y en referencia a los quipus, dirá que:

Los indios del Pirú, antes de venir los españoles, ningún género de escritura tuvo, ni por letras ni por caracteres, o cifras o figurillas, como los de la China y los de México; más no por eso conservaron menos la memoria de sus antiguallas, ni tuvieron menos su cuenta para los negocios de paz, y guerra y gobierno. (p. 385)

A continuación describe lo que son los quipus: "unos memoriales o registros hechos de ramales, en que diversos ñudos y diversas [sic] colores, significan diversas cosas" (Acosta, 1590, p. 385). Dice también: "los libros pueden decir historias, y leyes y ceremonias, y cuentas de negocios, todo eso suplen los quipos tan puntualmente que admira" (p. 385). Es decir, para Acosta los khipus no son ni escritura ni libros, pero funcionan como la escritura y los libros. Así establece la analogía:

Y en cada manojo de éstos, tantos ñudos y ñudicos, y hilillos atados; unos colorados, otros verdes, otros azules, otros blancos, finalmente tantas diferencias que así como nosotros de veinte y cuatro letras guisándolas en diferentes maneras sacamos tantas infinidad de vocablos, así estos de sus ñudos y colores, sacaban innumerables significaciones de cosas. (Acosta, 1590, p. 386)

Acosta hace referencia a la preservación de la memoria no solo mediante los quipus sino también mediante pinturas: "Fuera de esta diligencia, suplían la falta de escritura y letras, parte con pinturas como los de México, aunque las del Pirú eran muy groseras y toscas, parte a lo más con quipus" (Acosta, 1590, p. 385).

Sin embargo, también sabemos de la existencia de otras formas de registro; así, en la Historia de los Incas de Pedro Sarmiento de Gam- 
boa (1572) se atribuye a Pachacuti Inga Yupanqui el haber construido una suerte de historia oficial sobre tablones pintados:

Allegóse a esto la grandísima diligencia del Pachacuti Inga Yupangui, noveno inga, el cual hizo llamamiento general de todos los viejos historiadores de todas las provincias quél sujetó, y aun de otros muchos más de todos estos reinos, y túvolos en la ciudad del Cuzco mucho tiempo examinándolos sobre las antigüedades de sus historias, hízolo todo pintar por su orden en tablones grandes, y deputó en las Casas del Sol una gran sala, adonde las tales / tablas, que guarnescidos de oro estaban, estuviesen como nuestras librerías, y constituyó doctores que supiesen entenderlas y declararlas. Y no podían entrar, donde estas tablas estaban, sino el inga o los historiadores, sin expresa licencia del inga. (Sarmiento de Gamboa, [1572] 1942, pp. 46-47)

De la misma forma, en la Relación de las fabvlas i ritos de los Ingas de Cristóbal de Molina, el Cuzqueño (c. 1575) se afirma que:

Para entender donde tuuieron origen sus ydolatrias porque es assi q[ue] estos no usaron de escritura y tenian en vna casa de el Sol Llamada Poquen Cancha q[ue] es Junto aL Cuzco la uida de cada vno de los yngas y de las tierras $\mathrm{q}[\mathrm{ue}]$ conquisto pintado por sus figuras en vnas tablas, y $\mathrm{q}[\mathrm{ue}]$ origen tuuieron, y entre Las dichas pinturas tenian asimismo pintada La fabula sig/[uiente] En La uida de mango capac que ffue El primer ynca de donde enpeçaron A jatarse y llamarse Hijos del sol y a tener principio La ydolatria y adoracion Del Sol. (Molina c. 1575: ff. 1r.-1v.)

Estas formas de registro de la memoria serán pronto sancionadas y asignadas al rubro de la "antigua idolatría" india, razón por la que el Virrey Toledo la penará "en sus personas y bienes" o, caso contrario, promoverá su sustitución con simbología cristiana.

Item, porque de la costumbre envejecida que los indios tienen de pintar ídolos y figuras de demonios y animales a quien solían mochar en sus duhos, tianas, vasos, báculos, paredes y edificios, mantas, camisetas, lampas y casi en todas cuantas cosas les son necesarias, parece que en alguna manera conservan su antigua idolatría, proveeréis, en entrando en cada repartimiento, que ningún oficial de aquí adelante, labre ni pinte las tales figuras, so graves penas, las cuales ejecutaréis en sus personas 
y bienes lo contrario haciendo. Y las pinturas y figuras que tuvieren en sus casas y edificios, y en los demás instrumentos que buenamente y sin mucho daño se pudieren quitar y señalaréis que pongan cruces y otras insignias de cristianos en sus casas y edificios. (Toledo, 1569-1570, p. 39)

De igual forma, el dominico Meléndez ratifica el mandato de erradicar las mencionadas manifestaciones de la memoria:

Y assi se tiene mandado, que no solo en las Yglesias, sino en ninguna parte, ni publica, ni secreta de los pueblos de Yndios, se pinte el Sol, la Luna, ni las Estrellas; [...] por quitarles la ocasion de boluer (como esta dicho) à sus antiguos delirios, y disparates. (Meléndez, 1681, p. 62)

En este contexto, bajo el despliegue de la Conquista y teniendo como base los recursos de memoria citados, la población andina habría refuncionalizado su sistema religioso y cosmológico a partir de las normas religiosas católicas, conservando las formas de continuidad a través de un sistema escriturario tridimensional, tal como lo menciona Acosta (1590):

Fuera de estos quipos de hilo, tienen otros de pedrezuelas, por donde puntualmente aprenden las palabras que quieren tomar de memoria. Y es cosa de ver a viejos ya caducos con una rueda hecha de pedrezuelas, aprender el Padre nuestro, y con otra el Ave María, y con otra el Credo, y saber cuál piedra es que fue concebido de Espíritu Santo, y cuál que padeció debajo del poder de Poncio Pilato, y no hay más que verlos enmendar cuando yerran, y toda la enmienda consiste en mirar sus pedrezuelas. (p. 386)

En cuanto a la crónica de Guamán Poma de Ayala, un dato interesante es que al referirse el autor a los indios de entre 18 y 20 años que fungirían de mensajeros, muestra la imagen de un joven que tiene en su mano un khipu y un recuadro en la parte superior que dice "carta" (Guamán Poma 1615: fol.204), dando cuenta de la función comunicacional que cumplía dicho objeto. Otro aspecto a resaltar se encuentra en el folio en que se muestra al Inca hablando con las huacas; el texto dice: "Con todas las uacas habla el Ynga”. En este caso, el Inca les pide cuentas sobre fenómenos atmosféricos como la lluvia, el granizo y la helada. El texto citado está inserto en un dibujo en el que se ve una suerte de maqueta circular con las huacas en el piso, bajo el cerro uanacauri uaca (1615: fol. 203) (Fig. 1). 
Figura 1. "Capítulo de los ídolos, Vaca Billca Incap"

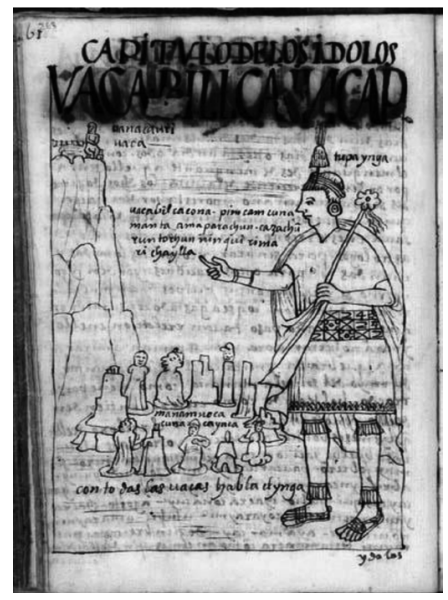

La crónica de Felipe Guamán Poma de Ayala (1615) resulta particularmente interesante no solo por lo que explícitamente dice sobre la escritura (cf. Quispe-Agnoli, 2006), sino por lo performativo de su propia escritura. En efecto, la obra de Guamán Poma es un extenso testimonio de las articulaciones entre escritura alfabética y no alfabética en los tempranos tiempos de la Colonia. ${ }^{1}$ Lo propio puede decirse algunas páginas de la Relación de Santa Cruz Pachacuti (c. 1613: fols. 8v, 13v, 14, 34).

Lo que poco se ha comentado es la lógica inversa de la relación entre escritura logográfica y escritura alfabética en la obra de Guamán Poma; es decir, la construcción de diseños logográficos a partir de las letras. Quispe-Agnoli $(2005,2006,2008)$ es la excepción. La autora muestra ejemplos de las páginas en las que el autor de la Nueva Coronica usa la escritura como mecanismo de construcción de diseños ideográficos, analizando, específicamente, el folio 923 en el que se diseña un tocapu con letras (Fig. 2).

1 Rolena Adorno (1986, pp. 109-157) ha estudiado la manera en que Guamán Poma usa la pictografía como forma de expresión del ordenamiento espacial andino. Véase, además, el trabajo de Quispe-Agnoli (2006). 
Figura 2. "Capítulo primero de las consideraciones"

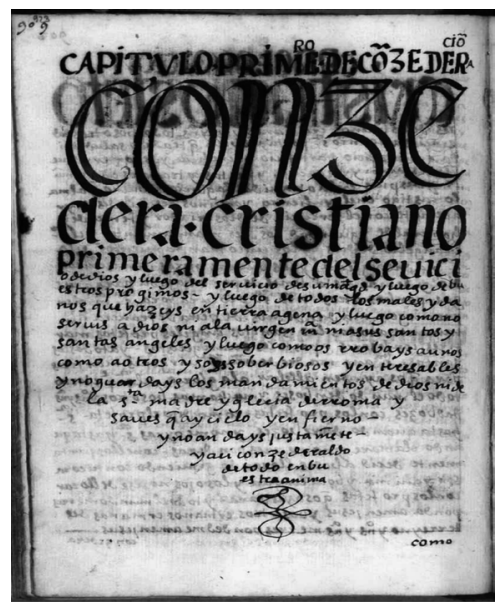

Guamán Poma 1615: fol. 923.

Además, hace referencia a la secuencia encontrada entre los folios 197-236, donde veinte páginas de la crónica se encuentran escritas según se muestra en la Fig. 3.

\section{Figura 3. "Tercero vecita"}

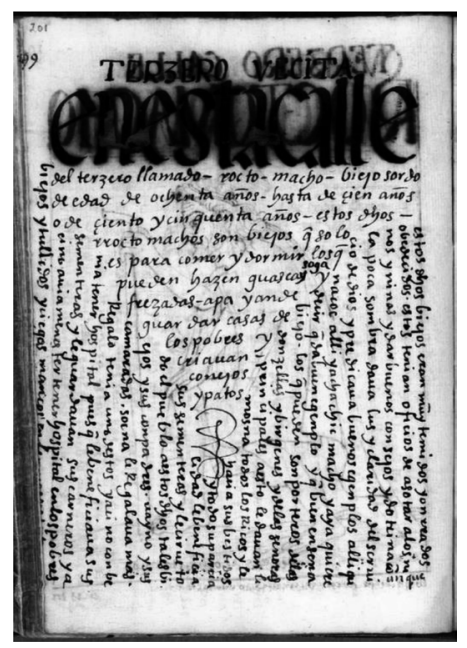


Si comparamos la imagen anterior, construida con letras, con los siguientes tocapus incaicos, en unku y en ch'uspa, veremos la similitud morfológica (Fig. 4 y 5 ).

Fig. 4. Unku ajedrezado con tocapu. Museo de Antropología, Arqueología e Historia del Perú.

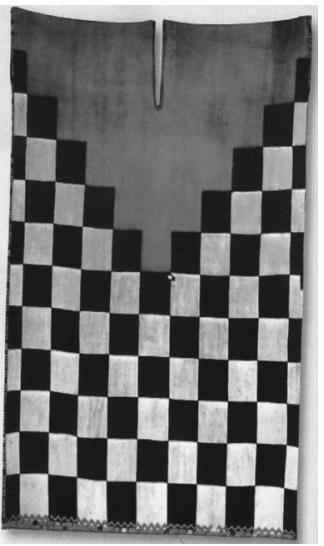

Tomado de De Rojas (2008, p. 20).

Fig. 5. Ch'uspa inca. Museo de Antropología, Arqueología e Historia del Perú.

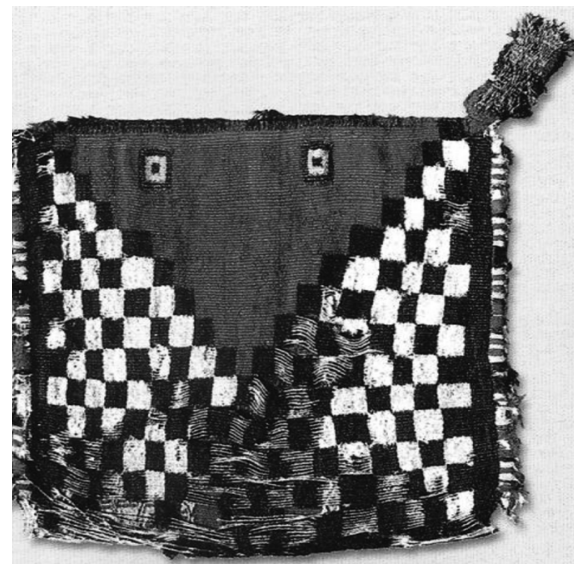


Sin embargo, sospechamos que el uso picto e ideográfico de la escritura alfabética, en la obra de Guamán Poma, va mucho más allá de los mostrado. En 443 páginas (37\%) de las 1189 que componen la Nueva Coronica se puede encontrar un uso de la escritura alfabética que rompe la normalidad formal de la misma. Más aún, si manipulamos los folios mencionados y los mostramos en una dirección diferente a la que normalmente recurrimos para "leer", encontraremos similitudes sorprendentes en cuanto a la elaboración de listas y bandas textiles (Fig. 6 a 9). ${ }^{2}$

Figuras 6 y 7. Arriba: fragmento de página "textil" de la Nueva Coronica de Guamán Poma de Ayala (1615: fol. 935). Abajo: ch'uspa. Estilo Yura. Horizonte Medio.

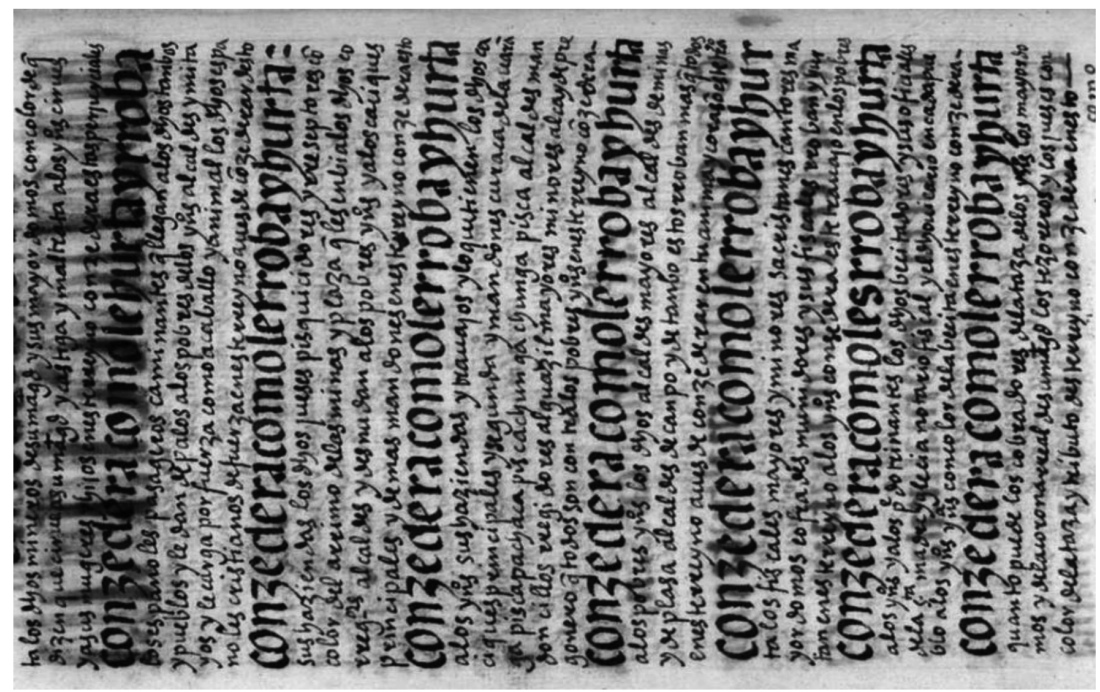

2 Otros ejemplos de esta escritura textil de Guamán Poma se pueden ver en Garcés (2014, pp. 140-143). 


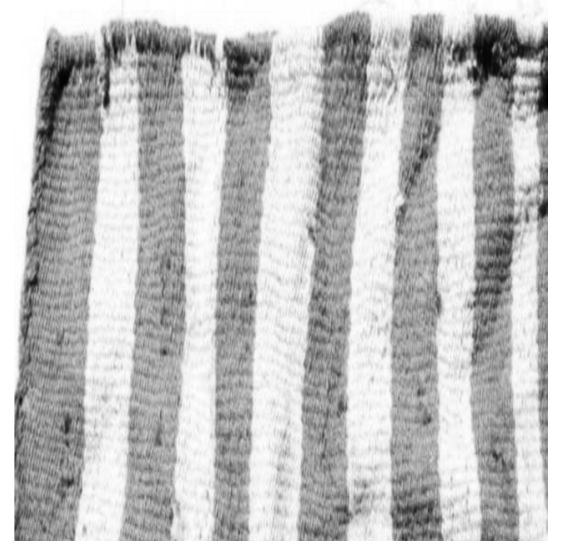

Colección INIAM-UMSS. Cod.: 330 INIAM (Catálogo INIAM) / Yura 43.

Figuras 8 y 9. Arriba: página "textil" de la Nueva Coronica de Guamán Poma de Ayala (1615: fol. 603). Abajo: Textil que reposa en The Metropolitan Museum of Art.

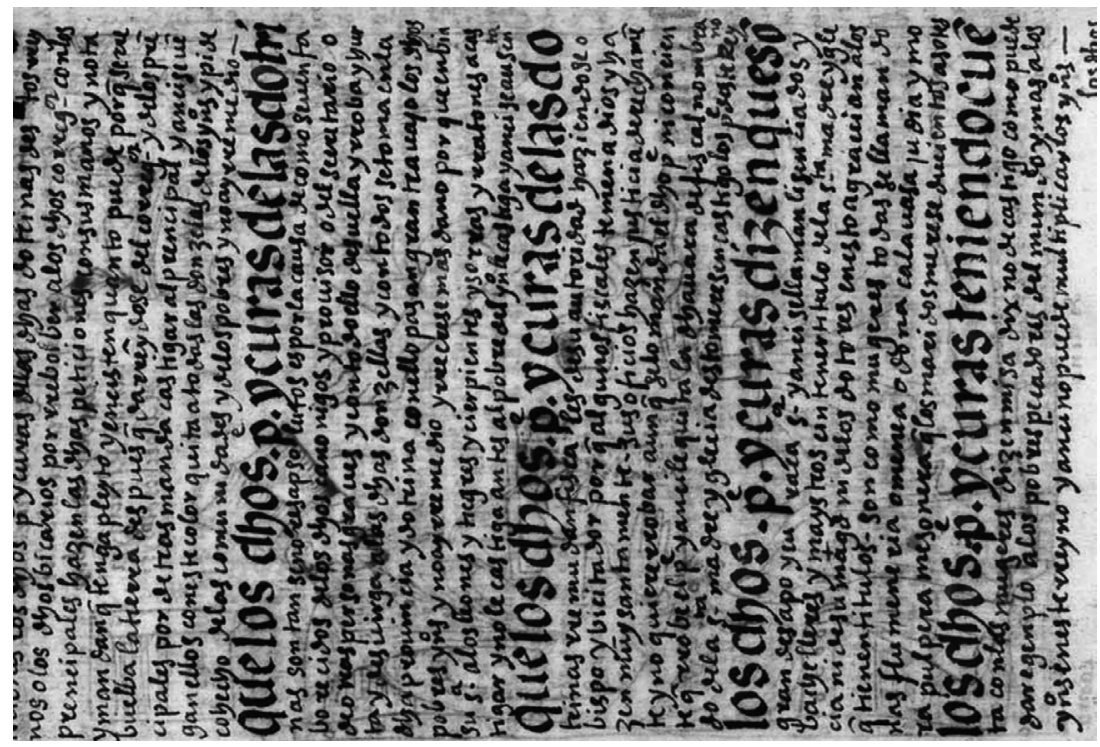




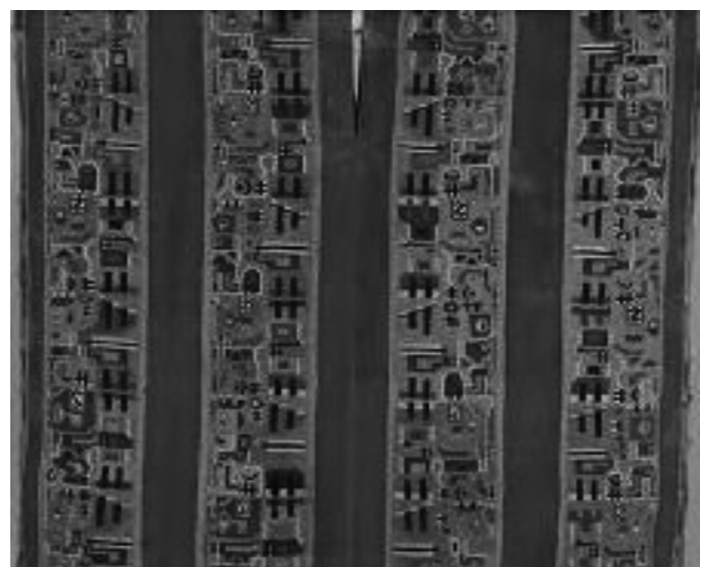

Tomado de la web ${ }^{3}$

Podría pensarse que estamos tratando de dar cuenta de hechos del pasado sin repercusiones en el presente. No es así. Indagaciones realizadas en Bolivia y Perú dan cuenta de la manera como distintas comunidades andinas recurren a mecanismos expresivos de memoria a través de textiles, varas, discos de barro y otros.

Uno de los lugares donde hoy se continúa una práctica escrituraria no alfabética es el Municipio de San Lucas en Chuquisaca (Bolivia). ${ }^{4}$ Este lugar es conocido por la histórica presencia de un tipo de elaboración escrituraria logográfica y tridimensional reportada desde hace, por lo menos, siete décadas. En su obra La escritura indígena andina (1953), Ibarra Grasso da cuenta de tal "hallazgo" en la década del 40 del siglo pasado. En el plano ideográfico dice que "se pintan sobre papel común, libretas y cuadernos comprados en el comercio, cuando no papeles de deshecho; en otros lugares en donde hemos estado, o hemos tenido noticias, se utilizan todavía los cueros, sobre cuyo lado interno se pintan los signos" (Ibarra, 1953, p. 14); de este tipo de material presenta y anali-

3 Consulta del 03/02/14: https://bit.ly/2ICWoCe

4 San Lucas es la capital de la segunda sección municipal de la Provincia Nor Cinti de Chuquisaca, a $3047 \mathrm{~m}$ de altitud promedio, denominada "capital del choclo y del durazno" (Garcés y Bustamante, 2015). Se ubica al sudoeste de la capital, Sucre. 
za un cuaderno perteneciente a Julián Herrera, ${ }^{5}$ un cuaderno procedente de Ocurí y un cuero elaborado por Porfirio Miranda.

Figura 10. Página del cuaderno de Julián Herrera con escritura no alfabética

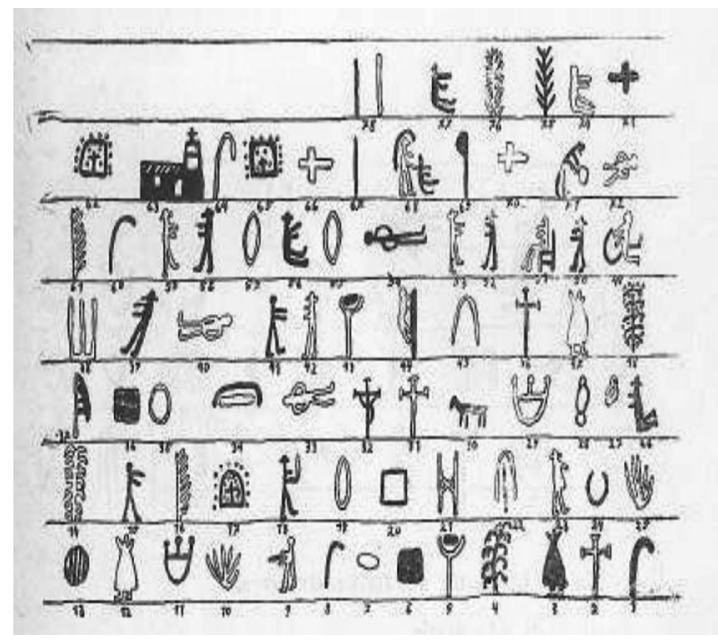

Ibarra, 1953, p. 190

En el presente se continúa una práctica de inscripción de la memoria a través de la elaboración de llut'asqas, discos de barro que contienen discursos religiosos católicos. Forman parte de rituales estacionales en cuanto al aprendizaje de los mismos y reproducen lo normado por la Iglesia colonial en el Tercer Concilio Limense. En este sentido, aunque pareciera tratarse de fórmulas producto del adoctrinamiento colonial, en realidad dan cuenta de la recreación adaptativa que despliegan continuamente las comunidades andinas (Garcés, 2017).

$5 \quad$ En el libro de Ibarra se habla del cuaderno de Julián Guerrero. En realidad se trata de Julián Herrera, comunario de Yapusiri, quien falleció el año 2000. De él se dice que no conocía la escritura de letra y tomaba apuntes "con dibujos" (Eugenio Clemente, comunicación personal, 01/11/2014). 
Figura 11. Disco de barro actual elaborado por Isidoro Flores (2014)

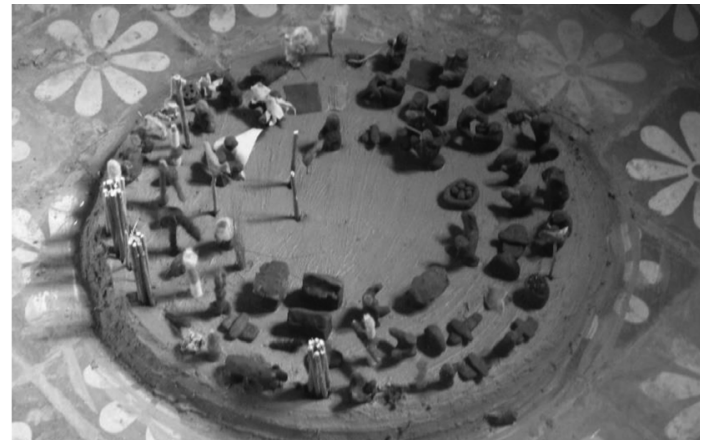

Foto: Fernando Garcés

Se trata de una escritura "comunal", fuera del control de la Iglesia, la Escuela formal y el Estado. Funciona como una escritura bi y tridimensional mnemónica que se articula a otros registros a partir de prácticas como el rebus y una multidireccionalidad conectada con la espacialidad textil y ritual, por un lado, y a la misma escritura alfabética, por otro. ${ }^{7}$

\section{Figura 12. Cuaderno de Don Santos Condori, Maestro Doctrinero de Ocurí, San Lucas (2014)}

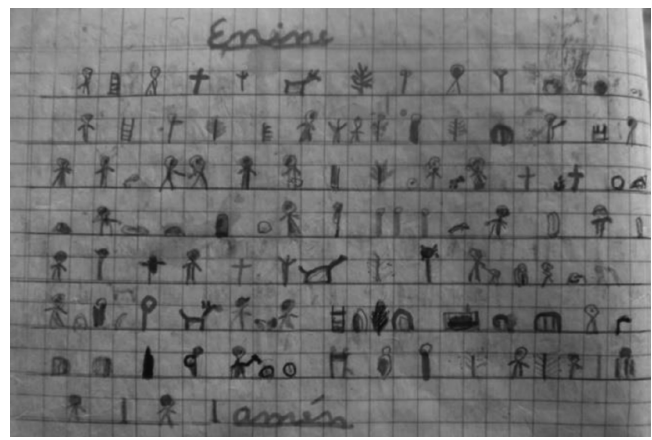

Foto: Soledad Guzmán

6 El rebus es un mecanismo a través del cual se evoca un concepto a través del sonido similar de otro término.

7 Sobre las prácticas escriturarias de San Lucas puede consultarse Castro (2015), Garcés (2014, 2015, 2016, 2017), Garcés y Bustamante (2015), Garcés y Sánchez (2016), García (2015), Ibarra (1953), INIAM (2015). 
Figura 13. Don Isidoro Flores enseñando los "rezos" a niñas de Padcoyo (2015)

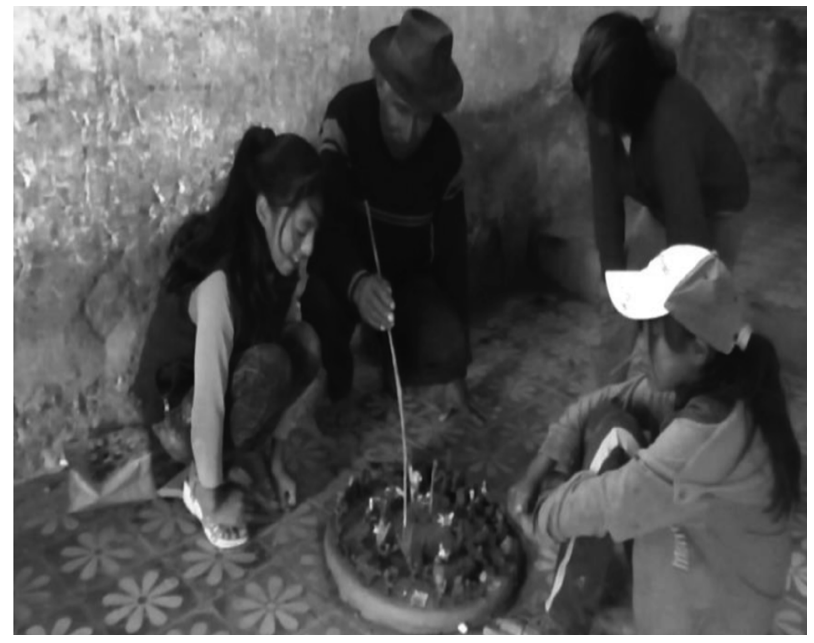

Figura 14. Niño y niña leyendo disco de barro. Padcoyo, San Lucas (2015)

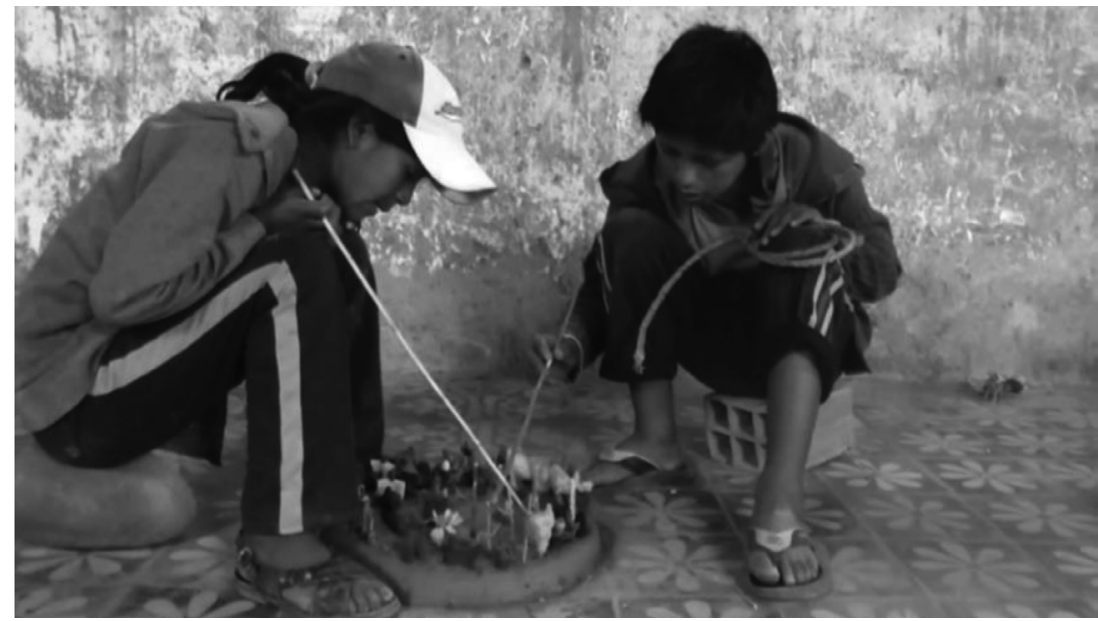

Foto: Fernando Garcés 


\section{Las fronteras de naturaleza y cultura}

El segundo caso de reflexión, sobre las posibilidades de apuntalar una interculturalidad epistémica, tiene que ver con las relaciones entre naturaleza y cultura.

La sistematización de lo considerado "naturaleza", en términos científicos, es un proyecto nuevo que se fraguó en el siglo XVIII en el marco de los viajes realizados por científicos europeos a distintas partes del mundo (Pratt, 2010). Esta visión se instauró en el ámbito epistémico de occidente. Veámoslo desde la perspectiva semiótica.

Umberto Eco dice que:

La ciencia natural, para dar razón de sus datos, produce símbolos (una ley expresada verbal o matemáticamente, un diagrama, una fórmula, etcétera). En cambio, las ciencias del hombre deben producir símbolos (teorías, interpretaciones) a propósito de sistemas de formas simbólicas. (Eco, 1985, p. 261)

En tal sentido, se puede establecer:

Una distinción semiótica entre ciencias de la naturaleza y ciencias de la cultura: las primeras son interpretaciones de datos, o interpretaciones de primer grado, las segundas son interpretaciones de interpretaciones, o interpretaciones de segundo grado (o, como veremos, de grado $n$ ). (Eco, 1985, p. 262)

La ciencia natural consistiría en interpretación de datos, aunque para realizar tal interpretación se requiere depender de ciertos supuestos filosóficos, ya que el dato es resultado de una interpretación perceptiva; sin embargo, en su proceder, la ciencia natural pone en tela de juicio los hábitos de la percepción cotidiana; aunque reconoce datos a partir de una hipótesis, trabaja con datos independientes de su observación. Las ciencias de la cultura o ciencias humanas, por el contrario, son interpretación de una práctica anterior, tienen por objeto una interpretación anterior:

Cuando la sociología estudia las funciones sociales, la antropología los sistemas de parentesco, la lingüística las reglas sintácticas, esas disciplinas explican el modo en que los seres humanos de determinado 
grupo actúan de conformidad con hábitos que son resultado de una interpretación de la realidad, aun cuando los sujetos no sean capaces de dar razón de ellos mediante interpretaciones posteriores (verbales, por ejemplo) rigurosamente organizadas. (Eco, 1985, p. 263)

Así, las ciencias de la cultura serían interpretaciones de segundo grado mientras las ciencias naturales lo serían de primer grado. ¿En qué sentido? En cuanto son interpretaciones:

de otros sistemas, o plexos de interpretaciones subyacentes. Por ejemplo, un antropólogo cultural observa que dos personas tienen comercio sexual mutuo y regular, viven en la misma cabaña, se ocupan en común de los hijos nacidos de su unión y realizan regularmente determinados gestos para con otras personas unidas a uno o al otro por vínculos de consanguineidad. Si el antropólogo se limitara a observar esos datos de comportamiento y a demostrar su regularidad, trabajaría aún en el nivel de las ciencias naturales (el científico natural no dice qué "pretenden» significar los cuerpos graves, cuando caen de acuerdo con ciertas leyes, sólo dice que caen de acuerdo con dichas leyes, y lo mismo haría el antropólogo, si se limitase a decir que los sujetos de su investigación actúan regularmente así). Sin embargo, el antropólogo intenta definir los datos que interpreta como otras tantas interpretaciones de la realidad (y hablará de comportamiento simbólico, de interacción significativa). Para hacerlo, puede recurrir a otros interpretantes. El significado de una acción dada puede interpretarse mediante otro comportamiento simbólico: el modo de disponer las cabañas de la aldea, por ejemplo; o mediante un comportamiento verbal del sujeto, quien declara que realiza ese gesto para con esa persona porque la reconoce como suegro. (Eco, 1985, pp. 263-264)

Lo dicho tiene relación con los desarrollos teóricos de las últimas décadas, al interior del debate antropológico, en las que varios autores afirman la diversidad no sólo en términos culturales sino ontológicos. Es lo que se ha llamado "el giro ontológico". En términos generales, éste "pretende disolver las certezas que forjó la modernidad sobre la naturaleza al juzgarlas reduccionistas, etnocéntricas, anticuadas y, hasta cierto punto, ingenuas" (Ruiz, \& del Cairo, 2016, pp. 194-195). Y es que en el llamado pensamiento occidental se ha instalado la idea de "naturaleza" vinculada a miradas antropocéntricas y racionalistas; ambas permitían 
asumirla como un objeto a ser dominado a fin de satisfacer las necesidades humanas (Ruiz \& del Cairo, 2016).

Así, Latour se pregunta si se debe creer o no en la realidad (Latour, 2001). Esto en relación a encarar la división entre el mundo de las cosas y el mundo de los hombres que la epistemología ha separado en base al acuerdo modernista; éste ha separado sociología, antropología, historia y filosofía de la ciencia y la tecnología. Se ha separado epistemología, ontología, psicología y política. De esta manera se ha establecido la división "afuera" (naturaleza), "adentro" (mente), "arriba" (Dios) y "abajo" (sociedad) ${ }^{8}$

Su trabajo resalta la agencia de los no humanos (Latour, 2001). ${ }^{9}$ Para ello los sigue, los rastrea en sus transformaciones y en las transformaciones que producen en los humanos; transformaciones que se van dando en cadena. Los no humanos son actantes, son todo tipo de "cosas", "objetos", "herramientas", "instrumentos" que usan los científicos para realizar sus investigaciones y que se convierten en sustancia, es decir, en aquello que permite construir sus acciones científicas. Le interesa ver cómo los científicos producen la naturaleza y la sociedad. En este sentido va el concepto de realidad de los estudios de la ciencia. No son estudios "realistas" en los que la realidad es algo externo a la actividad social de las personas y regulado por sus leyes. Tampoco es el realismo constructivista en el que la realidad se construye en la interrelación de las personas. Ambas posturas prestan atención a una ciencia purificada donde han sido demarcados a priori los polos de lo social y lo natural.

Latour cree que para entender el complejo entramado de sociedad, ciencia y tecnología es necesario ser a-moderno, no moderno, y adoptar una postura simétrica que preste atención a las relaciones de hibridación, dado que no es posible identificar y aislar elementos sociales, científicos o tecnológicos que sólo aparecen a posteriori cuando basa en la separación tajante entre naturaleza y cultura, mente y cuerpo, occidente y el resto, etc. (2014, p. 57).

9 Véase también Viveiros de Castro (2010, pp. 13-24), donde este autor dice que hay un "impresionante retorno de las cosas". 
purificamos ese entramado y eliminamos sus relaciones. En tal sentido, el científico debe dejar vivir las múltiples ontologías y prestar atención a las ontologías alternativas.

Descola, por su lado, define la ontología como "los sistemas de propiedades atribuidas a los existentes" (2012, p. 195). Este sistema de propiedades interviene en la determinación del tipo de relaciones posibles entre entidades humanas y no-humanas. La identificación y la relación son los mecanismos por los que establecemos continuidades y discontinuidades entre el mí mismo y los existentes. Descola plantea cuatro posibles modos de relación o "rutas ontológicas" que resultan de la clasificación de distintos seres en términos de sus atributos físicos (fisicalidad) y sus cualidades internas (interioridad). Esta suerte de dualismo transcultural refiere, en el caso de la fisicalidad:

A la forma exterior, la sustancia, los procesos fisiológicos, perceptivos y sensoriomotores, incluso el temperamento o la manera de actuar en el mundo, en cuanto manifiestan -se presume- la influencia ejercida sobre las conductas o los habitus por humores corporales, regímenes alimenticios, rasgos anatómicos o un modo de reproducción particulares. (Descola, 2012, p. 183)

La fisicalidad, entonces, no se refiere a la simple materialidad corporal sino al "conjunto de expresiones visibles y tangibles que adoptan las disposiciones propias de una entidad cualquiera cuando se las considera resultantes de las características morfológicas y fisiológicas intrínsecas de esa entidad" (Descola, 2012, p. 183).

La interioridad, por su parte, se entiende como:

Una gama de propiedades reconocidas por todos los seres humanos y que coinciden en parte con lo que solemos llamar 'espíritu', 'alma' o 'conciencia': intencionalidad, subjetividad, reflexividad, afectos, aptitud para significar o soñar. También pueden incluirse en el término los principios inmateriales a los que se considera causantes de la animación, como el aliento o la energía vital, a la vez que nociones aún más abstractas, como la idea de que comparto con otros una misma esencia, un mismo principio de acción o un mismo origen, en ocasiones objetivados en un nombre o un epíteto que nos resultan comunes. (Descola, 2012, p. 182) 
Las cuatro ontologías que propone Descola serían: animismo, totemismo, naturalismo y analogismo (Descola, 2011). En el animismo, los humanos y los no-humanos comparten una interioridad espiritual pero poseen cuerpos radicalmente diferentes. En el totemismo humanos y no-humanos están ligados entre sí por virtud de sus similitudes internas y físicas. En el naturalismo, los no-humanos y los humanos poseen atributos físico-químicos similares pero solamente estos últimos tienen espíritu y subjetividad. En el analogismo, humanos y no-humanos aparecen como un ensamblaje de esencias fragmentadas. Veámoslo en un esquema proporcionado por el mismo Descola:

\begin{tabular}{|c|c|}
\hline $\begin{array}{l}\text { Semejanza de las } \\
\text { interioridades } \\
\text { Diferencias de las } \\
\text { fisicalidades }\end{array}$ & Animismo \\
\hline $\begin{array}{l}\text { Diferencia de las } \\
\text { interioridades } \\
\text { Semejanza de las } \\
\text { fisicalidades }\end{array}$ & Naturalismo \\
\hline
\end{tabular}

\begin{tabular}{|l|c|}
\hline Totemismo & $\begin{array}{c}\text { Semejanza de las } \\
\text { interioridades } \\
\text { Semejanza de las } \\
\text { fisicalidades }\end{array}$ \\
\hline Analogismo & $\begin{array}{c}\text { Diferencia de las } \\
\text { interioridades } \\
\text { Diferencia de las } \\
\text { fisicalidades }\end{array}$ \\
\hline
\end{tabular}

Fuente: Descola, 2012, p. 190.

Como dicen Ruiz y Del Cairo (2016, p. 195), "Estas rutas ontológicas no constituyen sistemas puros ni cerrados que coincidan necesariamente con ciertas adscripciones identitarias o étnicas". En ciertas sociedades puede prevalecer cierta actitud ontológica que es, sin embargo, no excluyente, ya que cobija en sí otro tipo de valores o prácticas aparentemente contradictorios. Los autores citados mencionan, a manera de ejemplo, el hecho que en las sociedades urbanas puede tener más peso una ontología naturalista con respecto a los animales en el sentido que humanos y animales son especies biológicas que dependen de las mismas fuerzas evolutivas, sin embargo, sólo los humanos tienen conciencia alma y lenguaje. A pesar de ello, los humanos pueden establecer relaciones afectivas con sus mascotas al punto de hablarles y comportarse como si ellas fueran humanas (Ruiz \& Del Cairo, 2016). Lo 
mismo puede ocurrir en la relación de los artistas con sus instrumentos o de los artesanos con sus creaciones.

El aporte antropológico de Descola se desprende de la posibilidad de examinar la manera en que las distintas sociedades se relacionan con lo natural, problematizando así la clásica división entre naturaleza y cultura que heredó la modernidad. Pero además, las distintas concepciones de lo natural conllevará distintos modos de relacionamiento con lo no humano. Una naturaleza vista como objeto, o como "exterioridad" (Santos, 2003) implicará un tipo de acción sobre ella, diferente del caso en que los seres que habitan tal naturaleza son vistos como pares espirituales.

El antropólogo brasileño Viveiros de Castro, de otro lado, parte de la pregunta de qué le debe la antropología a los pueblos que estudia. Y su respuesta es que la antropología debe tomar al otro "en serio" (Viveiros de Castro, 2010): "es cuestión de darse (a sí mismo) los medios, o los instrumentos para poder tomar el pensamiento del otro en serio" (Viveiros de Castro, 2014, p. 238). En este sentido, "la distinción clásica entre Naturaleza y Cultura no puede ser utilizada para describir dimensiones o dominios internos a las cosmologías no occidentales sin pasar antes por una crítica etnológica rigurosa" (Viveiros de Castro, 2004, pp. 226). ${ }^{10}$

Para este autor, los regímenes ontológicos amerindios difieren de los de Occidente en las "funciones semióticas inversas atribuidas al cuerpo y el alma" (Viveiros de Castro, 2010, p. 28). Esto se entiende mejor a partir de los conceptos de perspectivismo y multinaturalismo propuestos por él.

El perspectivismo surge de numerosas referencias de la etnografía entre pueblos amazónicos a una concepción indígena:

Según la forma en que los seres humanos ven a los animales y otras subjetividades que pueblan el universo -dioses, espíritus, muertos, habitantes de otros niveles cósmicos, plantas, fenómenos metereológicos, accidentes geográficos, objetos y artefactos- es profundamente diferente

10 En portugués en el original. Traducción mía. 
del modo como los seres ven a los humanos y se ven a sí mismos. (Viveiros de Castro 2004, p. 227) ${ }^{11}$

Sin embargo, hay que tener claro que el perspectivismo no es relativismo; es la forma como humanos, animales y espíritus se ven a sí mismos y ven a los otros con los que se relacionan (Ruiz \& Del Cairo, 2016). El perspectivismo:

Se trata de una concepción común a muchos pueblos del continente, según la cual el mundo es habitado por diferentes especies de sujetos o personas humanas y no humanas que lo aprehenden según puntos de vista distintos. (Viveiros de Castro, 2004, p. 225) 12 $^{12}$

Como dicen Ruiz y Del Cairo (2016):

El perspectivismo amerindio puede ser sucintamente definido como una ontología en la que el mundo es aprehendido desde diferentes puntos de vista por diferentes clases de seres - cada uno de ellos provisto de conciencia y cultura-, quienes, a su vez, se perciben a sí mismos como humanos al tiempo que definen a otros seres como no-humanos. Hace énfasis en la noción de punto de vista, esto es, un conjunto de disposiciones perceptuales y afectivas que se encuentran arraigadas o incorporadas en cada sujeto. (p. 196)

Humanos y animales aprehenden el mundo bajo el mismo tipo de categorías (cultura). Lo que es diferente es el mundo que cada uno ve y ello está marcado por los diferentes cuerpos que habitan los distintos seres. Es decir, lo que une a humanos y no humanos es la cultura, no la naturaleza. Esto es así porque humanos, animales y espíritus habitan distintos cuerpos y configuran distintos tipos de naturalezas. Sin embargo, no se trata de una antropomorfización del mundo; es una interpretación del tipo de relaciones que pueden establecer los seres entre sí y con los que son pensados por ellos como distintos (Ruiz \& Del Cairo, 2016).

11 En portugués en el original. Traducción mía

12 En portugués en el original. Traducción mía. La referencia a un mundo habitado por distintos tipos de sujetos recuerda la visión tojolabal según la cual en el mundo no hay objetos sino sólo sujetos, aunque de clases muy diferentes (Lenkersdorf, 1996). 
De manera cercana, el autor propone el término multinaturalismo:

Para designar uno de los rasgos distintivos del pensamiento amerindio en relación con las cosmologías "multiculturalistas" modernas; en tanto estas últimas se apoyan en la implicación mutua entre la unicidad de la naturaleza y la multiplicidad de las culturas - la primera garantizada por la universalidad objetiva de los cuerpos y de la sustancia, la segunda generada por la particularidad subjetiva de los espíritus y los significados-, la concepción amerindia supondría por el contrario, una unidad del espíritu y una diversidad de los cuerpos. (Viveiros de Castro, 2010, p. 34)

Dicho de otra manera, las cosmologías multiculturalistas modernas:

Se apoyan en la implicación mutua entre unicidad de naturaleza y multiplicidad de culturas -la primera garantizada por la universalidad objetiva de los cuerpos y de la sustancia, la segunda generada por la particularidad subjetiva de los espíritus y del significado; [frente a ello] la concepción amerindia supondría, por el contrario, una unidad de espíritu y una diversidad de los cuerpos. La cultura o el sujeto serían aquí la forma de lo universal, la naturaleza o el objeto la forma de lo particular. (Viveiros de Castro, 2004, p. 226) ${ }^{13}$

El antropólogo colombiano Arturo Escobar desarrolla su crítica a la manera como se concibe la relación naturaleza-cultura en occidente desde la noción colonialidad de la naturaleza (Escobar, 2011). Ésta está marcada por las visiones mecanicistas de occidente sobre la naturaleza. Las principales características de la colonialidad de la naturaleza son: a) clasificación en jerarquías que ubica a los no-modernos, los primitivos y la naturaleza en el fondo de la escala clasificatoria; b) visiones esencialistas de naturaleza; c) subordinación del cuerpo y la naturaleza a la mente; d) visión de los productos de la tierra como subordinados al mercado impulsado por los humanos; e) ubicación de ciertas naturalezas fuera del mundo masculino eurocéntrico; f) subalternización de otras articulaciones de biología e historia a los regímenes modernos (Escobar, 2011, p. 51).

13 En portugués en el original. Traducción mía. 
Desde este posicionamiento establece el valor de lo que llama “ontologías relacionales". Se trata de ontologías:

En las cuales los mundos biofísicos, humanos y supernaturales no se consideran como entidades separadas, sino que se establecen vínculos de continuidad entre estos. Es decir, en muchas sociedades no-occidentales o no modernas, no existe la división entre naturaleza y cultu-/ra como la conocemos y, mucho menos, entre individuo y comunidad de hecho, no existe el "individuo" sino personas en continua relación con todo el mundo humano y no-humano, y a lo largo de los tiempos. (Escobar, 2014, pp. 58-59)

Esta mirada propone con fuerza, entonces, el principio de relacionalidad, según el cual "todas las cosas del mundo están hechas de entidades que no pre-existen a las relaciones que las constituyen" (Escobar, 2014, p. 58, resaltado en el texto).

Las ontologías relacionales se oponen a la ontología dualista de occidente en la que

El mundo está poblado por "individuos" que manipulan "objetos" y se mueven en "mercados", todos auto constituidos y auto regulados. En otras palabras, dentro de una ontología dualista, nos vemos como sujetos I autosuficientes que confrontamos o vivimos en un mundo compuesto de objetos igualmente autosuficientes que podemos manipular con libertad. (Escobar, 2014, pp. 57-58) ${ }^{14}$

Enfatiza el autor que las ontologías no hacen alusión a simples formas representativas, sino que crean verdaderos mundos. Así, en una ontología en la que la montaña es un ser inerte, un objeto sin vida, es fácil derivar prácticas extractivistas; en una ontología en la que la montaña es un ser sintiente se seguirán prácticas de relacionamiento con ella. Lo propio puede decirse de la intersubjetividad tojolabal en la que "la milpa se pone triste" y la tierra es considerada "Nuestra Madre"; por tanto, no puede ser comercializada (Lenkersdorf, 1996, pp. 106-119).

14 Enfatizado en el texto. 
Aquí conviene contraponer -y también complementar- la lectura antropológica a la mirada filosófica. En filosofía se considera que a partir de Heidegger (2003) se dio un giro ontológico; él vuelve a poner en el centro de la filosofía la pregunta por el ser. El Dasein de Heidegger se traduciría como ser-ahí pero referido al ser-en-el-mundo, ser en su práctica cotidiana de existir. El Dasein es el "hombre" existencial que se inquieta, se preocupa, se angustia, muere. Desde esta perspectiva, Heidegger cuestiona la noción de realidad objetiva propia de la metafísica; él apuesta por una ontología hermenéutica, de la interpretación, y no por una ontología metafísica de la verdad. En este sentido, los seres humanos vivimos en mundos interpretativos. Por ello, para el autor el lenguaje es la morada en la que habita el ser. Así, "A las significaciones les brotan palabras, en vez de ser las palabras las que, entendidas como cosas, se ven provistas de significaciones" (Heidegger, 2003, p. 180).

La hermenéutica de Gadamer (1977, 1992), por su parte, no es una simple cuestión de técnica, no se trata del método en sí mismo, sino una postura filosófica: se pregunta cuál es la constitución ontológica de la comprensión humana y que es lo que ocurre en nosotros más allá del querer y del hacer. Busca pensar lo que se produce cuando se comprende (Aguirre, 1998). Muy cerca de su maestro, Heidegger, Gadamer postula que el lenguaje humano es el fundamento último del ser; y lenguaje entendido a la manera del logos griego. Es el habla lo que distingue al hombre del animal: “¿Qué puede haber más convincente que la tesis de que el lenguaje de los animales, si se quiere llamar así a su modo de entenderse, difiere totalmente del lenguaje humano, capaz de representar y comunicar un mundo objetivo?" (Gadamer, 1992, p. 146).

Como se ve, el giro ontológico ya está presente en el debate filosófico desde hace casi un siglo. ${ }^{15}$ Sin embargo, se trata de una ontología absolutamente antropocéntrica: le otorga al ser humano la potestad total de pensar/mirar a los otros seres; no admite que otros seres puedan pensar/mirar a los seres humanos. Para Heidegger, los no-humanos pertenecen al estado óntico, no ontológico, el que le corresponde al humano

15 La primera edición de Ser y tiempo de Heidegger es de 1927. 
por inquietarse por su existencia en calidad de Dasein. Lo que además se ratifica en una concepción ontológica que hunde su fundamento en el lenguaje humano, como hemos visto en Gadamer. Pero, además, en el caso de Heidegger, hay un claro helenocentrismo y eurocentrismo desde el uso mismo del lenguaje: trabaja mucho con las etimologías tanto en alemán como en griego y les atribuye a estas dos lenguas una posición primordial en el quehacer filosófico (Steiner, 1983). Así, con respecto al griego, Heidegger dice que:

La lengua griega no es simplemente una lengua como las demás lenguas europeas que conocemos. La lengua griega, y solamente ella, es lôgos. [...] en el caso de la lengua griega lo dicho en ella es, al mismo tiempo y de un modo señalado, aquello que lo dicho nombra. (Heidegger, 2004, p. 42)

Como se ve, hay - efectivamente- un giro ontológico previo desde la filosofía, reconocido tímidamente por los autores vinculados a la antropología y la sociología que hemos citado. ${ }^{16}$ Sin embargo, esta mirada ontológica, fuertemente anclada en el lenguaje humano como fundamento del ser, no logra pensar más allá del ser humano como esencia última de la existencia.

Volviendo a la separación de lo natural y lo cultural, expresada en los tipos de ciencia explicitados por Eco (ver supra), ella recibe la interpelación de muchos pueblos indígenas que no conocen tal escisión. Así, sabemos que en el mundo andino los cerros se enamoran y las aguas se enojan; los elementos naturales como los árboles, las piedras, las nubes, etc. son enunciadores climáticos que expresan su conocimiento al ser humano, por explicitar solo unos pocos elementos.

En lo que sigue quisiera mostrar unos pocos ejemplos de cómo funciona esta vinculación de lo humano con lo no-humano en el mundo andino quechua a partir del lenguaje. Para ello, usaré referencias del Periódico Conosur Ñawpaqman, una revista bilingüe que se publica des-

16 Viveiros de Castro (2010, p. 87) hace alguna referencia a las relaciones entre antropología y filosofía en las últimas décadas, principalmente en el mundo anglosajón, y Arturo Escobar (2016) da cuenta de la influencia de Heidegger y Gadamer en autores que reflexionan sobre el "diseño ontológico". 
de hace más de treinta años en Cochabamba, Bolivia (Garcés, 2005). Las noticias y textos que se publican en dicha revista, en buena parte, se construyen sobre la base de una inscripción del discurso oral.

Como he mostrado en otro lugar (Garcés 2005), la base discursiva de dicha oralidad quechua es la elaboración metafórica de los hablantes. Si seguimos la pista ofrecida por Lakoff y Johnson (1980), las metáforas pertenecen al ámbito de la vida cotidiana y no son privilegio de los profesionales de la literatura. En tal sentido, los autores plantean una crítica tanto al objetivismo como al subjetivismo en filosofía y lingüística para, desde ahí, proponer como base de comprensión del mundo, un experiencialismo anclado en la cultura de los diversos grupos hablantes (Lakoff \& Johnson, 1980, pp. 228-282), lo cual calza bastante bien con el debate contemporáneo en torno al pluralismo ontológico.

Veamos entonces algunos ejemplos tomados del Conosur.

En primer lugar, y retomando lo enunciado, en el Periódico se encuentra una serie de testimonios que dan cuenta de la manera en que se comportan no humanos como los vientos, los árboles, las aguas y los químicos:

1, 2 agosto killapi muyuq wayritas puriykachan $(44$, p. 7$){ }^{1}$

Sach'asninchiqqa yarqhayninchiqta yachan (47, p. 12).

Sach'as yachanku (53, p. 7).

Papa pisita puqunanta tuna yachallantaq (53: 8).

[...] wakin yakusqa phiñas chullchuyachiwasunman $(35$, p. 7).

[...] kimikuqa jallp'aq misk' inta ch' unqaq kasqa (62, p. 14).

Kimikuqa jallp'ataqa k'aymayachin (49: 8).
Durante los días 1 y 2 de agosto caminan los vientos "vuelteros".

Los árboles conocen nuestra hambre.

Los árboles saben.

La tuna sabe de la poca producción de la papa.

Algunas aguas peligrosas (maléficas) nos pueden hacer enfermar.

El abono químico le ha sabido chupar su fertilidad [lit. 'su sabor, su dulce'] a la tierra.

El abono químico vuelve infértil a la tierra [lit. 'la vuelve desabrida']. 
En el último sentido, se afirma recurrentemente que la tierra, la naturaleza, el mundo, están cansados. ${ }^{17}$

Wakin kuraqkuna kay pacha kawsay sayk'usqa ninku (44, p. 7).

Pitaq juchayuq kay pacha sayk'usqa kananpaq? (46, p. 1).

Tiempo cambiasqaña, mundo q'ala sayk'usqa (160, p. 6).

\begin{abstract}
Algunos sabios dicen que el planeta está cansado.
\end{abstract}

¿Quién tiene la culpa de que esté cansada la naturaleza?

El tiempo ha cambiado; el mundo está totalmente cansado.

Lo más significativo, sin embargo, proviene de aquello que se suele denominar "predictores climáticos". En la concepción quechua, animales, elementos atmosféricos o astronómicos, minerales y vegetales predicen la calidad del ciclo agrícola. Así, el sonido o la calidad del sonido producido por zorros y toros, y las acciones del zorrino "avisan" si será buen año o año seco.
Atuqsituta fijakullankutaq septiembre 15
Se fijan si el zorro va a gritar (aullar) el 15 p'unchay chayta qhapariyqachanqa, t'ipi t'ipita qhapariyqachan chayqa, qaq, qaq, qaq nispa chayqa mana waliq watachu ninku, uk rikllata waqaqaqaqaqá niyku- rin chayqa waliq watapaq (157, p. 10).
San Juanpi, 1 de agosto ch' 'isi ima toros ulaptinkuqa, waliq wata kaq. Unayña mana uyarinichu, imachus kanpis atuqpis manaña waqanchu San Juan chaypaq chinkarpanchus imachus (157, p. 10). de septiembre. Si aúlla intermitentemente diciendo qaq, qaq, qaq, no será un buen año. Si aúlla de manera continua, diciendo qaqaqaqaqá, será un buen año.
Añathuyita t'aqraspi jallp'ata allasqa. Ch'aki watachá kanqa (157, p. 11).
Si en la noche del 1 de agosto, en San Juan, los toros mugen es para buen año. Antes no escuché. iQué será que ni los zorros aúllan! ¿Será que ya se perdieron para San Juan?
El zorrino ha cavado la tierra. Parece que será un año seco.

Uno de los indicadores en los que más se confía, que mejor comunica, diríamos, son las nubes.

17 Una ontología similar se encuentra entre los tojolabales. Véase Lenkersdorf (1996, pp. 106-112). 
Phuyupi qhaway mana fallanchu, junt'akunpuni (157, p. 10).

Phuyu yachallantaq para kananpaq (160, p. 6).
El mirar en las nubes no falla, siempre se cumple.

Las nubes también saben si va a haber lluvia.

La observación de las nubes, sin embargo, está vinculada a uno de los meses claves de la predicción climática: agosto.

Qhawasqaman jinaqa 1 de agostopi mana phuyu kanchu para pisicha kanqa, ajiman jina qhawakuchkan, mana phuyu kaqtin parapis pisipuni, phuyu sumaqtapuni yachan chayllatapuni nuqa qhawariyta yachani tiempo q'ala sayk'usqa (160, p. 6).
Al mirar el 1 de agosto, si no hay nubes va a haber poca lluvia; así se ve. Si no hay nubes habrá poca lluvia. Las nubes saben bien; yo sé mirar eso: que el tiempo está cansado.

En agosto también se observa la sudoración de las piedras.

Agosto killapi 1, 2, 3 p'unchaykuna rumi jump'in, allin wata kananpaqqa, kay wata mana jump'inchu, paranqapis saqra paraslla chamuwasunchis (160, p. 6).
Los días 1, 2 y 3 del mes de agosto suda la piedra para que sea buen año. Esto año no sudó la piedra. Nos van a llegar escasas lluvias.

Junio es otro mes importante para la observación, en este caso, de las pléyades. Su luminosidad comunicará la bondad del año agrícola.

Juniopi cabrilla sumaq ch' uwita lluqsimullantaq, yuraqsituta k'anchamurqa, waliq watapaq (157, p. 10).
En junio salió muy clarito la cabrilla (las pléyades). Blanquito alumbró para que sea buen año. 


\section{2}

En cuanto a la vegetación, es clara la idea de que ella sabe, predice y comunica el "buen año".

Sach'akuna waliq wata waqyamuchkawanchik (53, p. 8).

Durazno t'ika yachan, uramanta qallarichkan, chayqa kusa wata kananpaq, qayna wata puntamanta t'ikayta qallarinqa chayrayku ch'aki wata karqa (160, p. 6).
Los árboles predicen un buen año [lit. nos llaman un buen año].

La flor de durazno sabe. Si está empezando (saliendo) desde abajo es para que sea buen año. El año pasado empezó a florecer desde arriba por eso fue un año seco.

La producción comunicativa no humana requiere, sin embargo, ser leída, decodificada, a través de la articulación de los diversos elementos.

Waliqlla kay wataqa kanqa. Chiripis kasallan, rit'iramun imaqa. Rumista tiqrarirqani junp' isqa karqa 1 de agostopipis. Todos Santospaqqa parawasunñacha. Napis thaqus t'ikasankuña, chaypi rikukuchkan, paykunaqa Santa Rosa pasaytaraq t'ikaq kanku kunanqa khuskan t'ikaypiña kachkankuqa, paritas ñawpamunqa. Phuyupis 2 de agostomanta jaqayman phuyumurqaña, q'alata rit'iraykun patasmanpisqaí (157, p. 10).
Este será un buen año. Hay frío; está despejado. Di vuelta a las piedras y estaban transpiradas el 1 de agosto. Para Todo Santos va a llover. Los espinos ya están floreciendo; así se ve. Los espinos todavía para Santa Rosa recién florecían, pero ahora están a la mitad de su florecimiento; las lluvias se van a adelantar. Para el 2 de agosto ya había nubes de lluvia; todo está alumbrando despejado.

\section{Conclusión}

Por un lado, nos enfrentamos al problema de cómo podemos pensar en un auténtico diálogo de saberes desde el lugar de la escritura alfabética que funciona como absoluto epistemológico, como la condición dominante de explicitación de los saberes del denominado mundo occidental. ¿O es que acaso existe la posibilidad de pensar la ciencia, la filosofía y el saber del mundo moderno fuera de la escritura alfabética? ¿Acaso existe o puede existir algo parecido al "conocimiento occidental" sin escritura alfabética? Incluso las formas discursivas del saber occidental, que con mucha seguridad tuvieron su origen en formas orales, se expresan en el papel, en la letra. 
Por otro lado, es necesario reflexionar sobre cómo podemos pensar la interculturalidad epistémica en un mundo signado por diversas concepciones de la naturaleza y la cultura. ¿Cómo podemos aprender de otras ontologías que nos invitan a repensar la relación con la naturaleza, fuente de acumulación en el capitalismo extractivista contemporáneo?

“¡Y qué saben ellos!” es una canción de Tamara Castro. Es la expresión que muchos personajes de ciencia emitimos cuando nos referimos a los legos de la academia. Pero también podría ser la pregunta silenciosa que nos hacen quienes construyen, luchan y acarician la realidad desde otros mundos comprensivos y expresivos.

Es probable, entonces, que, como decía Carlos Lenkersdorf (2008), solo tengamos que "aprender a escuchar".

\section{Agradecimiento}

Esta comunicación, más que cierre de un ciclo, constituye la retribución mínima de una deuda agradecida hacia las personas de las que y con las que aprendí tanto en Bolivia durante dieciocho años. Los dos "casos" aquí presentados, el de la escritura no alfabética y el de las concepciones andinas de la naturaleza en el Conosur, son reelaboraciones de investigaciones realizadas en dos momentos y en dos instituciones que me permitieron trabajar estos temas junto con la gente de San Lucas, Raqaypampa y Ayopaya: el Instituto de Investigaciones Antropológicas y Museo de la Universidad Mayor de San Simón, entre 2010 y 2017, y el Centro de Comunicación y Desarrollo Andino, entre 1999 y 2008. Las instituciones las forman las personas y lamentablemente es imposible nombrarlos uno por uno y una por una. A todos y todas los que compartimos camino en esos tiempos y lugares, ¡anchata agradeceykichik!

Quito, Pawkar Raymi, 2018

\section{Bibliografía}

Acosta, J. de (1590). Historia natural o moral de las Indias. Edición de José Alcina Franch. Madrid: Dastin (2002).

Adorno, R. (1986). Guamán Poma. Literatura de resistencia en el Perú colonial. México: Siglo XXI ( $1^{\text {a }}$ ed. en español, 1991). 


\section{4}

Agazzi, E. (2002). El desafío de la interdisciplinariedad: dificultades y logros. Revista Empresa y Humanismo, 2, 241-252.

Aguirre, J. M. (1998). Hans-Geor Gadamer: la alternativa "ontológica" hermenéutica. Brocar, 21, 427-441.

Albó, X. (1999). Iguales aunque diferentes. Hacia unas políticas interculturales y lingüísticas para Bolivia. La Paz: CIPCA.

Arnold, D. (2012). El textil y la documentación del tributo en los Andes: los significados del tejido en contextos tributarios. Lima: Fondo Editorial de Asamblea Nacional de Rectores.

Bouysse-Cassagne, Th. (2000). Les mots, les morts et l'ecriture: arts de la mémorie et évangelisation dans les andes. Cahiers des Amériques Latines, $33,57-84$.

Bray, T. (2004). La alfarería imperial Inka: una comparación entre la cerámica estatal del área del Cuzco y la cerámica de las provincias. Chungara, 36(2), 365-374.

Burns, W. (1981). Introducción a la clave de la escritura secreta de los incas. Boletín de Lima, 12-14.

Castro, D. (2015). Escritura signográfica andina: los significados andinos y católicos de los signos signográficos consignados en la subcolección Osvaldo Sánchez Terrazas de cuero y papel del INIAM-UMSS y la colección privada de cueros de Walter Sánchez Canedo. Tesis de licenciatura. Cochabamba: LAEL, INIAM-UMSS.

Castro-Gómez, S. (2005a). La poscolonialidad explicada a los niños. Popayán: Universidad del Cauca, Instituto Pensar.

(2005b). La hybris del punto cero. Ciencia, raza e ilustración en la Nueva Granada (1750-1816). Bogotá: Editorial Pontificia Universidad Javeriana.

(2007). Decolonizar la universidad. La hybris del punto cero y el diálogo de saberes. En Santiago Castro-Gómez y Ramón Grosfoguel (Eds.), El giro decolonial. Reflexiones para una diversidad epistémica más allá del capitalismo global (pp. 79-91). Bogotá: Siglo del Hombre, Universidad Central, IESCO, Instituto Pensar.

Cereceda, V. (2010). Semiología de los textiles andinos. Chungara, 42(1), 181198.

Chirinos, A. (2010). Quipus del Tahuantinsuyo. Curacas, Incas y su saber matemático en el siglo XVI. Lima: Comentarios. 
Coronil, F. (2000). Listening to the Subaltern: Postcolonial Studies and the Neocolonial Poetics of Subaltern States. En Laura Chrisman y Benita Parry (Eds.), Postcolonial Theory and Criticism (pp. 37-55). Cambridge: The English Association.

Cruz, P. (2016). Imágenes en pugna. Reflexiones en torno a las producciones visuales indígenas en el ámbito de la minería colonial. Boletín del Museo Chileno de Arte Precolombino, 21(1), 95-113.

Curatola, M. \& de la Puente J. C. (2013). Contar concertando: quipus, piedritas y escritura en los Andes coloniales. En Marco Curatola y José Carlos de la Puente (Eds.), El quipu colonial. Estudios y materiales (pp. 193243). Lima: PUC-P.

DeFrancis, J. (1989). Visible Speech. The diverse onenees of writing systems. Honolulu: University of Hawai Press.

Déléage, P. (2013). Inventer L'Ecriture. Rituels prophétiques et chamaniques des Indiens d'Amérique du Nord, XVIIe-XIXe siècles

De Rojas, D. (2008). Los tokapu. Graficación de la emblemática Inka. La Paz: CIMA.

Derrida, J. (1967a). De la gramatología. México: Siglo XXI (5ª ed. en español, 1998).

(1967b). La escritura y la diferencia. Barcelona: Anthropos (1989).

Descola, P. (2011). Más allá de la naturaleza y de la cultura. En Leonardo Montenegro (Ed.), Cultura y naturaleza. Aproximaciones a propósito del bicentenario de la independencia de Colombia (pp. 75-97). Bogotá: Jardín Botánico de Bogotá José Celestino Mutis.

(2012). Más allá de naturaleza y cultura. Buenos Aires: Amorrortu.

Díaz-Polanco, H. (2006). Elogio de la diversidad. Globalización, multiculturalismo y etnofagia. México: Siglo XXI.

Eco, U. (1985). Signos, peces y botones. Apuntes sobre semiótica, filosofía y ciencias humanas. En De los espejos y otros ensayos. Barcelona: Lumen.

Escobar, A. (2011). Epistemologías de la naturaleza y colonialidad de la naturaleza. Variedades de realismo y constructivismo. En Leonardo Montenegro (Ed.), Cultura y naturaleza. Aproximaciones a propósito del bicentenario de la independencia de Colombia (pp. 50-72). Bogotá: Jardín Botánico de Bogotá José Celestino Mutis.

(2014). Sentipensar con la tierra. Nuevas lecturas sobre desarrollo, territorio y diferencia. Medellín: Ediciones UNAULA. 


\section{6}

(2016). Autonomía y diseño: la realización de lo comunal. Popayán: Universidad del Cauca.

Fernández, M. (2004). Interdisciplinariedad en ciencias sociales: perspectivas abiertas por la obra de Pierre Bourdieu. Cuadernos de Trabajo Social, 17, 169-193.

Fornet-Betancourt, R. (2001). Transformación intercultural de la filosofía. Bilbao: Desclée de Brouwer.

Fuller, Norma (Ed.) (2005). Interculturalidad y politica: Desafíos y posibilidades. Lima: Red para el Desarrollo de las Ciencias Sociales en el Perú.

Gadamer, H.-G. (1977). Verdad y método I. Salamanca: Sígueme (2003). (1992). Verdad y método II. Salamanca: Sígueme (1998).

Garcés, F. (1997). Síntesis histórica de la lingüística y sus corrientes. En Fernando Garcés y Catalina Álvarez, Lingüística Aplicada a la Educación Intercultural Bilingüe (pp. 7-135). Quito: Abya-Yala.

(2005). De la voz al papel. La escritura quechua del Periódico CONOSUR Nawpaqman. La Paz: Plural, CENDA.

(2009). ¿Colonialidad o interculturalidad? Representaciones de la lengua y el conocimiento quechuas. La Paz: PIEB, UASB.

(2010). Los esfuerzos de construcción descolonizada de un Estado Plurinacional en Bolivia y los riesgos de vestir al mismo caballero con otro terno. En Raquel Yrigoyen (Ed.), Pueblos indígenas: Constituciones y Reformas Politicas en América Latina (pp. 213-241). Lima: ILSA, INESC, IIDS.

(2011). Identidades políticas: del ñuqayku al ñuqanchik y viceversa. Arqueoantropológicas, 1(1), 119-128. Cochabamba: INIAM-UMSS.

(2014). Aprender otra(s) escritura(s) en los Andes: una invitación a repensar la pedagogía desde la etnografía. Arqueoantropológicas, 4, 113-160.

(2015). 'Solo con la cabeza no se puede recordar'. Oralidades, escrituras y memorias enmarañadas en San Lucas (Chuquisaca). En Fernando Garcés y Walter Sánchez (Eds.), Textualidades: entre cajones, textiles, cueros, papeles y barro. Cochabamba: INIAM-UMSS.

(2016). El lugar de la escritura católica andina en las escrituras logográficas. Arqueoantropológicas, 6(6), 89-110.

(2017). Escrituras andinas de ayer y de hoy. Cochabamba: INIAM-UMSS. 
Garcés, F. \& Bustamante M. (2015). La escritura en discos de barro del INIAMUMSS. En Escritura andina: pictografía e ideografía en cuero, papel y barro. Cochabamba: INIAM-UMSS (2a ed.).

Garcés, F. \& Guzmán S. (2003). Educacionqa kawsayninchikmanta kawsayninchikpaq kanan tiyan. Elementos para diversificar el currículo de la $\mathrm{Na}$ ción Quechua. Sucre: CENAQ.

Garcés, F. \& Sánchez W. (2016). Inscripciones y escrituras andinas: un sistema complejo y denso de visualidades, oralidades y espacialidades. Boletín del Museo Chileno de Arte Precolombino, 21(1), 115-128.

García, A. (2015). Variantes escritas y orales de los rezos de pascuas en el Municipio de Vitichi. En Fernando Garcés y Walter Sánchez (Ed.), Textualidades: entre cajones, textiles, cueros, papeles y barro (pp. 123-148). Cochabamba: INIAM-UMSS.

García, R. (2011). Interdisciplinariedad y sistemas complejos. Revista Latinoamericana de Metodología de las Ciencias Sociales, 1(1), 66-101.

Goody, J. (1968). Introducción. En Jack Goody (Comp.), Cultura escrita en sociedades tradicionales (pp. 11-38). Barcelona: Gedisa, (1 a ed., 1996).

Guamán Poma de Ayala, F. (1615). Nueva Coronica y Buen Gobierno (The Guaman Poma Website: https://bit.ly/2X153gp consulta febrero 2013).

Harris, R. (1955). Signos de escritura. Barcelona: Gedisa (1999).

Heidegger, M. (2003). Ser y tiempo. Madrid: Trotta (3a ed., 1a reimpr., 2014).

(2004). ¿Qué es la filosofía? Barcelona: Herder (1ª ed., 2a reimpr., 2006).

Ibarra, D. (1953). La escritura indígena andina. La Paz: Alcaldía Municipal de La Paz.

INIAM (2015). Escritura andina: pictografía e ideografía en cuero, papel y barro. Cochabamba: INIAM-UMSS (2 ${ }^{\text {a }}$ ed. ampliada).

Jara, V. de la (1975). Introducción al estudio de las escrituras de los inkas. Lima: INIDE.

Jaye, B. \& Mitchel, W. (1999). Introduction. En Barbara Jaye y William Mitchel (Eds.), Picturing Faith. A Facsimile edition of the Pictographic Quechua Catechism in the Huntington Free Library (pp. 5-13). Bronx: Huntington Free Library.

Kymlicka, W. (1995). Ciudadanía multicultural. Una teoría liberal de los derechos de las minorías. Barcelona: Paidós (1 1a ed., 1996). 
(2001). La política vernácula. Nacionalismo, multiculturalismo y ciudadanía. Barcelona: Paidós (2003).

Lakoff, G. \& Johnson, M. (1980). Metáforas de la vida cotidiana. Madrid: Cátedra (4a ed., 1998).

Landaburu, J. (1998). Oralidad y escritura en las sociedades indígenas. En Luis Enrique López e Ingrid Jung (Eds.), Sobre la huellas de la voz. Sociolingüística de la oralidad y la escritura en su relación con la educación (pp. 39-79). Madrid, Cochabamba, Bonn: Morata, PROEIB Andes, DSE.

Lander, E. (1995). Las transformaciones postmodernas de la política. Ponencia presentada en el XX Congreso de la Asociación Latinoamericana de Sociología. México, 2 al 6 de octubre de 1995.

Latour, B. (2001). La esperanza de Pandora. Ensayos sobre la realidad de los estudios de la ciencia. Barcelona: Gedisa.

Lenkersdorf, C. (1996). Los hombres verdaderos. Voces y testimonios tojolabales. México: Siglo XXI (2a ed., 1999).

(2008). Aprender a escuchar. Enseñanzas maya-tojolabales. México: Plaza y Valdés.

Leff, E. (2015). De la multi a la inter y a la transdisciplina: especializaciones e hibridaciones entre ciencias sociales, ciencias ambientales y ecología humana. En Arturo Argueta y Guillermo Peimbert (Coords.), La ruptura de las fronteras imaginarias o de la multi a la transdisciplina (pp. 41-59). México: UNAM, Siglo XXI.

Lewellen, T. (2003). Introducción a la antropología política. Barcelona: Bellaterra (3a ed., 2009).

López, L. E. (1998). Literacidades y Educación Intercultural Bilingüe en la subregión andina. Lengua y cultura mapuche, 8, 9-47.

Lyotard, J.-F. (1990). La condición posmoderna. Informe sobre el saber. México: REI.

Maldonado, C. (2009). Complejidad de los sistemas sociales: un reto para las ciencias sociales. Cinta de Moebio, 36, 146-157.

Mallon, F. (2001). Promesa y dilema de los Estudios Subalternos: Perspectivas a partir de la historia latinoamericana. En Ileana Rodríguez (Ed.), Convergencia de tiempos: estudios subalternos/contextos latinoamericanos. Estado, cultura y subalternidad (pp. 117-154). Amsterdam, Atlanta: Rodopi. 
Martínez, J. L., Díaz, C., Tocornal, C., \& Arévalo, V. (2014). Comparando las crónicas y los textos visuales andinos. Elementos para un análisis. Chungara, 46(1), 91-113.

Meléndez, J. (1681). Tesoros verdaderos de la Yndias. Tomo segundo. Roma.

Molina, Ch. de (c. 1575). Relacion de fabvlas i ritos de los Ingas hecha por Christoual de molina cura de laperroquia de N.Sa de los Remedios de el Hospital de los Naturales de la ciudad de el Cuzco dirigida al reuerendissimo Señor Obispo don Sebastian de el Artaum del consejo de su Mag[esta]d. Biblioteca Nacional. Mss 3169.

Morin, E. (1999). La cabeza bien puesta. Repensar la reforma, reformar el pensamiento. Buenos Aires: Nueva Visión (1a ed., 5a reimpr., 2002).

Murúa, M. de [c. 1615] (2008). Historia General del Piru. Facsimile of J. Paul Getty Museum Ms. Ludwig XIII 16. Los Angeles: Getty Research Institute.

Orejuela, J. (2009). Primero afirmar, luego integrar. La interdisciplinariedad y las ciencias sociales. Revista Cientifica Guillermo de Ockham, 7(1), 41-56.

Orellana, R. (2004). Interlegalidad y campos jurídicos. Discurso y derecho en la configuración de órdenes semiautónomos en comunidades quechuas de Bolivia. Cochabamba: Huella Editores.

Pachacuti Yamqui Salcamaygua, Joan de Santa Cruz (c. 1613). Relacion de antiguedades deste reyno del Piru. Estudio etnohistórico y lingüísticos de Pierre Duviols y César Itier. Lima, Cuzco: IFEA, CBC (1993).

Paz, S. (2005a). Ideas preliminares para pensar la política de la diferencia. En Luis Enrique López y Pablo Regalsky (Eds.), Movimientos indígenas y Estado en Bolivia (pp. 97-103). La Paz: PROEIB Andes, CENDA, Plural.

(2005b). Reflexiones sobre la interculturalidad y el conflicto. En Carlos Vacaflores (Coord.), Conflicto y colaboración en el manejo de recursos naturales (Experiencias de Bolivia y Argentina) (pp. 61-74). Tarija: JAINA.

(2006). Desandando los caminos de la interculturalidad: una aproximación a la educación intercultural bilingüe. En Alejandra Ramírez (Comp.), Escuelas y procesos de cambio (pp. 125-150). Cochabamba: CESU.

Pratt, M. L. (2010). Ojos imperiales. Literatura de viajes y transculturación. México: FCE.

Quispe-Agnoli, R. (2005). Cuando Occidente y los Andes se encuentran: Qellqay, escritura alfabética y tokhapu en el siglo XVI. Colonial Latin American Review, 14(2), 263-298. 
(2006). La fe andina en la escritura: resistencia e identidad en la obra de Guamán Poma de Ayala. Lima: UNMSM.

(2008). Para que la letra lo tenga en los ojos: tocapu, emblemas y letreros en los Andes coloniales del siglo XVII. En Paola González Carvajal y Tamara Bray (Eds.), Lenguajes visuales de los incas (pp. 133-145). Oxford: British Archeological Reports.

Rodrigo, M. (1999). La comunicación intercultural. Barcelona: Anthropos.

Ruiz, D., \& Del Cairo, C. (2016). Los debates del giro ontológico en torno al naturalismo moderno. Revista Estudios Sociales, 55, 193-204. http:// dx.doi.org/10.7440/res55.2016.13, consulta 05/10/17.

Salomon, F. (2004). The cord keepers, Khipus and Cultural Life in a Peruvian Village. Durham and London: Duke University Press.

Santos, B. de Sousa (2000). Crítica de la razón indolente. Bilbao: Desclée de Brouwer.

(2003). La caída del Angelus Novus: ensayos para una nueva teoría social y una nueva práctica política. Bogotá: ILSA, Universidad Nacional de Colombia.

Sarmiento de Gamboa, P. [1572] (1942). Historia de los incas. Buenos Aires: Emecé (2a ed., 1943).

Steiner, G. (1983). Heidegger. México: FCE (2005).

Szemiński, J. (2010). ¿Qué sabemos de quillqa en Qulla Suyu? Estudios Latinoamericanos, 30, 129-186.

Taylor, Ch. (1992). El multiculturalismo y "la politica del reconocimiento". México: FCE.

Toledo, F. de (1569-1570). Instrucción General para los visitadores. En Disposiciones gubernativas para el Virreinato del Perú (1569-1574) (pp. 1-39). Sevilla: Escuela de Estudios Hispano-Americanos (1986).

Urton, G. (1998). From Knots to Narratives: Reconstructing the Art of Historical Record Keeping in the Andes from Spanish Transcription of Inca Khipus. Ethnohistory, 45(3), 409-438.

Vattimo, G. (2000). Posmoderno. ¿Una sociedad transparente? En Benjamín Arditi (Ed.), El reverso de la diferencia. Identidad y política (pp. 15-22). Caracas: Nueva Sociedad. 
Viaña, J., Claros, L., Estermann, J., Fornet-Betancourt, R., Garcés, F., Quintanilla, V., \& Ticona, E. (2009). Interculturalidad crítica y descolonización. Fundamentos para el debate. La Paz: III-CAB.

Viveiros de Castro, E. (2004). Perspectivismo e multinaturalismo na América indígena. O que nos faz pensar, 18, 225-254.

(2010). Metafísicas caníbales. Lineas de antropología postestructural. Madrid:Katz.

(2014). Llevar a serio... Contra el infierno metafísico de la antropología. Entrevista con Eduardo Viveiros de Castro. Anales de Antropología, 48(II), 219-244.

Wade, P. (1997). Raza y etnicidad en Latinoamérica. Quito: Abya-Yala.

Walsh, C. (2001). La interculturalidad en la educación. Lima: DINEBI.

(2002). La problemática de la interculturalidad y el campo educativo.

Ponencia presentada en el Congreso de la OEI Multiculturalismo, identidad y educación, 16 de abril de 2002.

Walzer, M. (1997). Tratado sobre la tolerancia. Paidós: Barcelona (1ª ed., 1998).

Wallerstein, I. (Coord.) (1996). Abrir las ciencias sociales. Informe de la Comisión Gulbenkian para la reestructuración de las ciencias sociales. México: Siglo XXI.

Wallerstein, I. (1998). Impensar las ciencias sociales. Limites de los paradigmas decimonónicos. México: Siglo XXI.

Wieviorka, M. (2001). La diferencia. La Paz: Plural.

Winand, J. (2013). Les Hiéroglyphes Égyptiens. París: Presses Universitaires de France.

Zecchetto, V. (2002). La danza de los signos. Nociones de semiótica general. Quito: Abya- Yala.

Ziólkowski, M., Arabas, J., \& Szemińki, J. (2008). La historia de los qerus: apuntes acerca de la relación entre las representaciones figurativas y los signos tocapus. En Paola González Carvajal y Tamara Bray (Eds.), Lenguajes visuales de los Incas (pp. 163-176). Oxford: British Archeological Reports. 